Nova Southeastern University

Florida

NSUWorks

12-10-2015

\title{
Direct Phenotypic Screening in Mice: Identification of Individual, Novel Antinociceptive Compounds from a Library of 734821 Pyrrotidine Bis-piperazines
}

Richard A. Houghten

Torrey Pines Institute for Molecular Studies

Michelle L. Ganno

Torrey Pines Institute for Molecular Studies

Jay P. McLaughlin

Torrey Pines Institute for Molecular Studies

Colette T. Dooley

Torrey Pines Institute for Molecular Studies

Shainnel O. Eans Torrey Pines Institute for Molecular Studies

See next page for additional authors

Follow this and additional works at: https://nsuworks.nova.edu/math_facarticles

Part of the Chemistry Commons, Mathematics Commons, and the Medicine and Health Sciences Commons

\section{NSUWorks Citation}

Houghten, Richard A.; Ganno, Michelle L.; McLaughlin, Jay P.; Dooley, Colette T.; Eans, Shainnel O. Torrey Pines Institute for Molecular Studies; Santos, Radleigh; LaVoi, Travis; Nefzi, Adel; Welmaker, Greg; Giulianotti, Marc A.; and Toll, Lawrence, "Direct Phenotypic Screening in Mice: Identification of Individual, Novel Antinociceptive Compounds from a Library of 734821 Pyrrolidine Bis-piperazines" (2015). Mathematics Faculty Articles. 240.

https://nsuworks.nova.edu/math_facarticles/240

This Article is brought to you for free and open access by the Department of Mathematics at NSUWorks. It has been accepted for inclusion in Mathematics Faculty Articles by an authorized administrator of NSUWorks. For more information, please contact nsuworks@nova.edu. 


\section{Authors}

Richard A. Houghten, Michelle L. Ganno, Jay P. McLaughlin, Colette T. Dooley, Shainnel O. Eans Torrey Pines Institute for Molecular Studies, Radleigh Santos, Travis LaVoi, Adel Nefzi, Greg Welmaker, Marc A. Giulianotti, and Lawrence Toll 


\title{
Direct Phenotypic Screening in Mice: Identification of Individual, Novel Antinociceptive Compounds from a Library of 734821 Pyrrolidine Bis-piperazines
}

\author{
Richard A. Houghten,* Michelle L. Ganno, Jay P. McLaughlin, Colette T. Dooley, Shainnel O. Eans, \\ Radleigh G. Santos, Travis LaVoi, Adel Nefzi, Greg Welmaker, Marc A. Giulianotti, and Lawrence Toll
}

Torrey Pines Institute for Molecular Studies, 11350 Southwest Village Parkway, Port St. Lucie, Florida 34987, United States

Supporting Information

ABSTRACT: The hypothesis in the current study is that the simultaneous direct in vivo testing of thousands to millions of systematically arranged mixture-based libraries will facilitate the identification of enhanced individual compounds. Individual compounds identified from such libraries may have increased specificity and decreased side effects early in the discovery phase. Testing began by screening ten diverse scaffolds as single mixtures (ranging from 17340 to 4879681 compounds) for analgesia directly in the mouse tail withdrawal model. The "all X" mixture representing the library TPI-1954 was found to produce significant antinociception and lacked respiratory depression and hyperlocomotor effects using the Comprehensive Laboratory Animal Monitoring System (CLAMS). The TPI-1954 library is a pyrrolidine bis-piperazine and totals 738192 compounds. This library has 26 functionalities at the first three positions of diversity made up of 28392 compounds each $(26 \times 26 \times 42)$ and 42 functionalities at the fourth made up of 19915 compounds each $(26$ $\times 26 \times 26$ ). The 120 resulting mixtures representing each of the variable four positions were screened directly in vivo in the mouse $55{ }^{\circ} \mathrm{C}$ warm-water tail-withdrawal assay (ip administration). The 120 samples were then ranked in terms of their antinociceptive activity. The synthesis of 54 individual compounds was then carried out. Nine of the individual compounds produced dose-dependent antinociception equivalent to morphine. In practical terms what this means is that one would not expect multiexponential increases in activity as we move from the all-X mixture, to the positional scanning libraries, to the individual compounds. Actually because of the systematic formatting one would typically anticipate steady increases in activity as the complexity of the mixtures is reduced. This is in fact what we see in the current study. One of the final individual compounds identified, TPI 2213-17, lacked significant respiratory depression, locomotor impairment, or sedation. Our results represent an example of this unique approach for screening large mixture-based libraries directly in vivo to rapidly identify individual compounds.

KEYWORDS: opioid, in vivo high-throughput screening, mixture-based combinatorial libraries, analgesia

\section{INTRODUCTION}

Although opioids are the front line therapeutics used for the treatment of significant pain, their use is limited by adverse side effects that include respiratory depression, tolerance, psychological effects and addiction. These have serious consequences for both individuals and society. ${ }^{1}$ Notwithstanding years of study, there continues to be a need for novel chemical entities demonstrating potent analgesia in conjunction with lacking the classic side effects of the currently utilized opiate therapeutics. A common reality is that the majority of preclinical drug candidates do not exhibit desirable drug-like properties and have significant side effect profiles at later stages of testing. This results in a high rate of attrition in the traditional drug discovery process 2008. ${ }^{2}$ To circumvent a number of the limitations of existing in vitro screening methods, we have developed a platform technology that permits the testing of tens of thousands to tens of millions of compounds as mixtures directly in animal models of disease. The use of systematically arranged libraries in positional scanning format. ${ }^{3-5}$ enables the identification of active functionalities at each variable position in a given molecule. This in turn, enables individual compounds to be readily identified, synthesized, and tested for their analgesic properties.

Mixture-based synthetic libraries are highly effective tools for generating novel lead compounds in a fraction of the time and cost of equivalent individual compound arrays. ${ }^{6-9}$ These large libraries are composed of linear peptides (tens of millions to trillions), cyclic peptides (5-10 million), peptidomimetics (millions), as well as 7-8 million heterocyclic compounds, ${ }^{10-12}$ and trillions of nona-and deca-peptides. ${ }^{13}$ Such mixtures are

Received: August 14, 2015

Revised: December 9, 2015

Published: December 10, 2015 

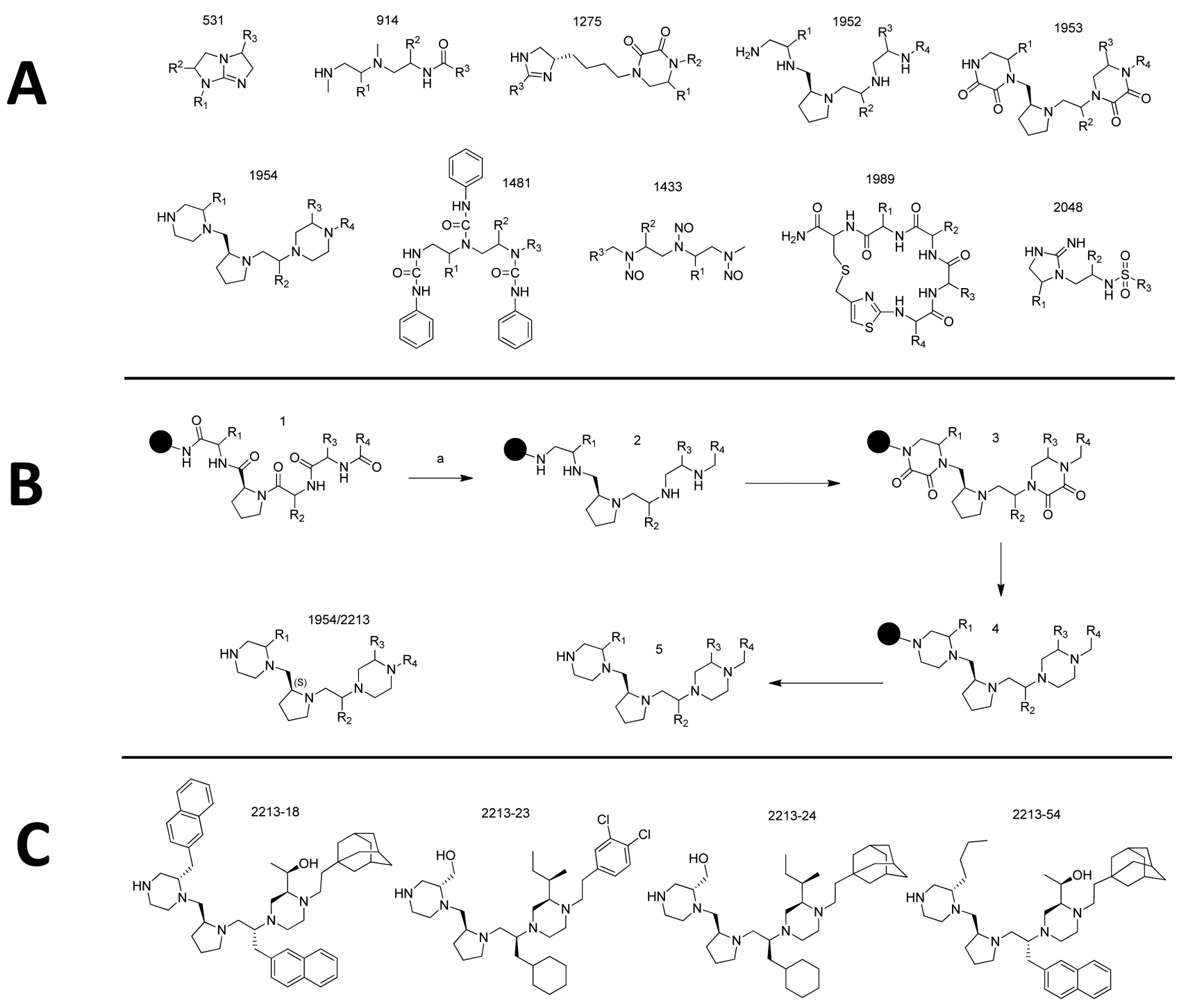

Figure 1. (A) Structures of core scaffolds for 10 scaffold ranking library samples. (B) Synthetic scheme for library 1954 and individual compounds 2213: the starting $\mathrm{N}$-acylated tetrapeptide, 1 , is reduced to the linear polyamine by diborane-THF followed by piperidine treatment to disrupt borane-amine complexes. The next step (b) involved treatment on the resin attached polyamine with oxalyldiimidazole/DMF, to form the bis diketopiperizone (c). This was then again reduced by diborane to yield the desired bispiperazine (d). This synthesis is described in Nefzi et al. 2009. ${ }^{20}$ Throughout this manuscript TPI 1954 library samples and 2213 individual compounds have the core scaffold shown in the second row, far left structure. (C) Structures for individual compounds 2213-18, 2213-23, 2213-24, and 2213-54.

effective because the most active compounds in a given mixture drive the activity found when such mixtures are tested. ${ }^{14,15}$ These systematically arranged mixtures are utilized since it is, at best, impractical for any laboratory to screen such large numbers of individual compounds directly in vivo.

We have previously reported a proof of concept of this approach by successfully identifying novel individual heterocyclic small molecule opioid analgesics and peptides by utilizing this mixture-based synthetic combinatorial strategy. ${ }^{16,17}$ In our earlier work, the in vivo screening of the positional scanning library TPI 1955 (a bis-cyclic guanidine library; ${ }^{18}$ resulted in the identification of two novel opioid analgesics, 1818-101 and 1818-109. These were found to produce antinociception equivalent to, or better than, morphine without the liabilities of respiratory depression or conditioned place preference.

Our working hypothesis is that the direct in vivo screening of systematically arranged small molecule and peptide mixturebased combinatorial libraries would yield more advanced therapeutically useful individual compounds possessing favorable analgesic properties with decreased side effects. An important additional value we have found is that novel antinociceptive compounds that have unknown targets are also identified. Using the scaffold ranking technique, ${ }^{7}$ ten structurally diverse small-molecule combinatorial libraries included bicyclic guanidines, permethylated polyamines, diketopiperazines, nitrosamines, phenylureas, cyclic thiazoles, and cyclic guanidines (Figure 1A) were tested for their antinociceptive properties in mice. These libraries ranged in total number from a low of 17340 to 4879681 . Each of these libraries were tested initially as single "all X" mixtures ${ }^{7}$ in mice for antinociceptive activity. Two recognized opioid liabilities, respiratory depression and locomotor activity, were also monitored.

Applying this strategy in the current study, we used the scaffold ranking technique ${ }^{7}$ with ten differing libraries in mice. Ten small-molecule combinatorial libraries were tested in this 
A

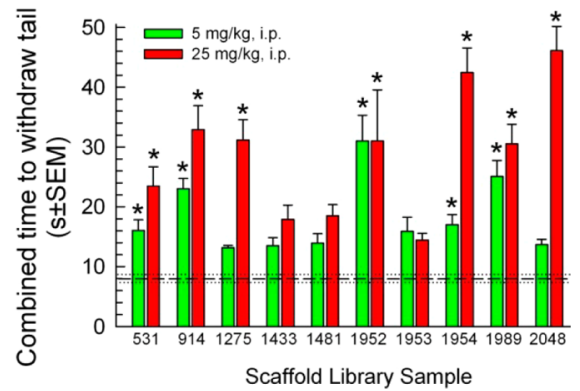

B

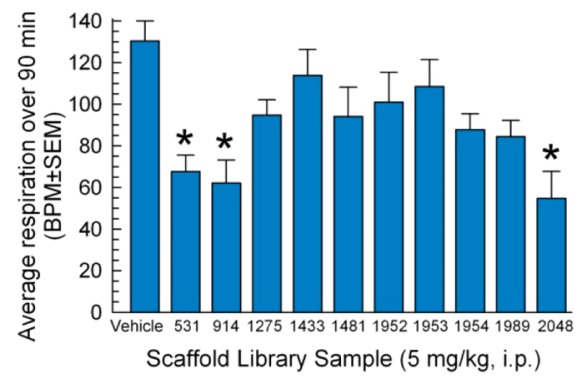

Figure 2. Scaffold ranking of libraries 531, 914, 1275, 1952, 1953, 1954, 1481, 1433, 1989, and 2048. (A) Screening by in vivo of antinociception response in the mouse $55{ }^{\circ} \mathrm{C}$ warm water tail-withdrawal test. All mixture-based samples were administered at a dose of $5 \mathrm{mg} / \mathrm{kg}$, i.p. (green bars) and $25 \mathrm{mg} / \mathrm{kg}$ i.p. (red bars). For structures of the libraries see Figure 1. Response to vehicle (10\% DMSO, i.p.) represented as dashed line; dotted lines represent SEM. Data represent average $( \pm$ SEM) summed tail-withdrawal latencies calculated by taking the sum of the average tail withdrawal latencies for each animal from each time point over a 24 -h period. Bars $=7-8$ mice each. B: Screening by respiration response. All mixture-based samples were administered at a dose of $5 \mathrm{mg} / \mathrm{kg}$, i.p.; vehicle (10\% DMSO, i.p.) was administered as a control. Data represent average $( \pm$ SEM) respiration rate (in breaths per minute, BPM) over a 90 min period. Bars $=8$ mice each, except vehicle, which was 40 mice. *Significantly different from response to vehicle, $p<0.05$, one-way ANOVA followed by Dunnett's post hoc test.

study, TPI 531, 914, 1275, 1952, 1953, 1954, 1481, 1433, 1989, and 2048 (Figure 1), were tested initially as ten single mixture samples for both antinociceptive activity and the known opioid liabilities of respiratory depression and locomotor activity.

The most active of these sample mixtures in analgesic assays without concordant liabilities, the 1954 series, was then analyzed using the positional scan approach ${ }^{3-7,19}$ to determine the most active antinociceptive functional groups driving the activity at each of the four positions of this scaffold (Figure 4A-D). The 1954 library is built around a core pyrrolidine bispiperazine scaffold (Figure 1) with 26 different functionalities at each of the first three diversity positions and 42 functionalities at the fourth position (Figure 4). This results in a total of 120 mixtures making up this library. Each mixture varies from 17576 compounds (position four) to 28392 (positions 1-3) compounds each, for a total of 738,192 compounds. The most active mixtures in the 120 mixtures making up library 1954 enabled the identification of those functionalities to be used to synthesize individual compounds defined in all four positions, termed the 2213 series. Individual compounds from the 2213-series were compared to morphine in the mouse $55^{\circ} \mathrm{C}$ warm water tail-flick test and also evaluated for their effects on respiration rate and locomotor activity.

\section{RESULTS}

Ranking the Ten Scaffolds for Antinociceptive Potency and Potential Liabilities. The scaffold ranking approach was used to determine the optimal library for in depth screening each scaffold was represented by a single mixture made up of all components of a particular library. ${ }^{7,8,14-16}$ The antinociceptive activity of the ten separate "all X" library scaffolds (531, 914, 1275, 1952, 1953, 1954, 1481, 1433, 1989, and 2048; see Figure 1) were first evaluated. Administration of the ten samples $(25 \mathrm{mg} / \mathrm{kg}$, i.p., Figure $2 \mathrm{~A}$, red bars) significantly increased the combined time mice required to remove their tails from a noxious stimulus of $55^{\circ} \mathrm{C}$ warm water (one-way ANOVA $F_{(10,74)}=11.12, p<0.0001$ with Dunnett's multiple comparisons post hoc test; red bars, Figure 2A).

Each of these 10 scaffolds were then tested at a lower dose (5 $\mathrm{mg} / \mathrm{kg}$, Figure 2A, Green Bars). The lower dose screening reduced the number of samples producing a significant antinociceptive effect response (one-way ANOVA $F_{(10,77)}=$
10.38, $p<0.0001$ ), with libraries 531, 914, 1952, 1954, and 1989 had significant activity $(p<0.05$, Dunnett's multiple comparisons post hoc test; green bars, Figure 2A). Library 1952 had clear toxicity at $25 \mathrm{mgs} / \mathrm{kg}$, but no toxicity or behavioral effects at $5 \mathrm{mgs} / \mathrm{kg}$. Also, library 2048 was nominally the most active, but was found to cause significant respiratory depression (Figure 2B). The respiratory effects found for library 2048 may be associated with mu opiate activity and will be evaluated in a separate study.

Of the remaining scaffold samples (1275, 1954, and 1989), the sample representing the 1954 library produced the greatest magnitude of antinociceptive activity (one-way ANOVA $F_{(2,21)}$ $=3.41, p=0.05)$, establishing this scaffold for further evaluation in the current study. Nonparametric bootstrapping analysis ${ }^{37}$ confirmed that the 1954 samples were unlikely to exhibit hyperlocomotion (a 32\% chance) or respiratory depression (a $30 \%$ chance), and second most likely to be more active than morphine (at $5 \mathrm{mg} / \mathrm{kg}$, i.p.; Figure 3).

In Vivo Positional Scanning of the 1954 Series Library. Utilizing the positional scanning approach, ${ }^{4,19}$ the antinociceptive activity of each of the 120 mixture-based samples comprising the 1954 series library was evaluated after administration $\left(5 \mathrm{mg} / \mathrm{kg}\right.$, i.p.) with the $55{ }^{\circ} \mathrm{C}$ warm-water tailwithdrawal assay (Figure 4). The combined time mice demonstrated to withdraw their tail was summed over the seven time points examined for each sample tested and is reported by substitution position (Figure 4A-D). Notably, a number of samples defined at each substitution position increased the combined time for tail withdrawal.

Nonparametric probabilistic analysis was also performed for each sample in the full positional scanning format. This predicted the likelihood of a given mixture containing functionalities that would be more active than the scaffold alone (Figure 5). Levels of probability values varied from position to position; two samples in $\mathrm{R}_{2}$ had a greater than $50 \%$ chance of exceeding the activity of an all $\mathrm{X}$ sample (Figure $5 \mathrm{~B}$ ), while 11,14 , and 27 were above $50 \%$ in positions $R_{1}, R_{3}$, and $\mathrm{R}_{4}$, respectively (Figure $5 \mathrm{~A}, \mathrm{C}$, and $\mathrm{D}$ ). Although this analysis generally mirrored the relative numbers of elevated results described at each position in the antinociceptive testing, probability rank ordering at each position varied slightly from median rank ordering, indicating some asymmetric variability to 


\begin{tabular}{|c|c|c|c|c|c|}
\hline \multicolumn{6}{|c|}{$\begin{array}{l}\text { Density Estimated Probabilities that Experimental Value } \\
\text { Exceeds } 5 \mathrm{mg} / \mathrm{kg} \text { Morphine }\end{array}$} \\
\hline \multirow{2}{*}{ Library } & \multirow{2}{*}{$\mathrm{mg} / \mathrm{kg}$} & \multicolumn{2}{|c|}{ CLAMS } & \multicolumn{2}{|c|}{ Combined Time to } \\
\hline & & Locomotion & Respiration & Median & Probability \\
\hline \multirow{2}{*}{531} & 5 & \multirow{2}{*}{$7 \%$} & \multirow{2}{*}{$7 \%$} & 14.8 & $0 \%$ \\
\hline & 25 & & & 20.2 & $4 \%$ \\
\hline \multirow{2}{*}{914} & 5 & \multirow{2}{*}{$2 \%$} & \multirow{2}{*}{$9 \%$} & 24.2 & $0 \%$ \\
\hline & 25 & & & 36.2 & $29 \%$ \\
\hline \multirow{2}{*}{1275} & 5 & \multirow{2}{*}{$21 \%$} & \multirow{2}{*}{$31 \%$} & 12.7 & $0 \%$ \\
\hline & 25 & & & 32.5 & $18 \%$ \\
\hline \multirow{2}{*}{1433} & 5 & \multirow{2}{*}{$37 \%$} & \multirow{2}{*}{$59 \%$} & 13.2 & $0 \%$ \\
\hline & 25 & & & 16.0 & $0 \%$ \\
\hline \multirow{2}{*}{1481} & 5 & \multirow{2}{*}{$41 \%$} & \multirow{2}{*}{$39 \%$} & 12.4 & $0 \%$ \\
\hline & 25 & & & 18.1 & $0 \%$ \\
\hline \multirow{2}{*}{1952} & 5 & \multirow{2}{*}{$19 \%$} & \multirow{2}{*}{$52 \%$} & 34.6 & $24 \%$ \\
\hline & 25 & & & 22.5 & $26 \%$ \\
\hline \multirow{2}{*}{1953} & 5 & \multirow{2}{*}{$15 \%$} & \multirow{2}{*}{$49 \%$} & 15.5 & $0 \%$ \\
\hline & 25 & & & 14.5 & $0 \%$ \\
\hline \multirow{2}{*}{1954} & 5 & \multirow{2}{*}{$6 \%$} & \multirow{2}{*}{$22 \%$} & 16.0 & $0 \%$ \\
\hline & 25 & & & 44.0 & $63 \%$ \\
\hline \multirow{2}{*}{1989} & 5 & \multirow{2}{*}{$16 \%$} & \multirow{2}{*}{$19 \%$} & 25.4 & $2 \%$ \\
\hline & 25 & & & 27.6 & $14 \%$ \\
\hline \multirow{2}{*}{2048} & 5 & \multirow{2}{*}{$8 \%$} & \multirow{2}{*}{$11 \%$} & 12.9 & $0 \%$ \\
\hline & 25 & & & 50.7 & $76 \%$ \\
\hline
\end{tabular}

Figure 3. Nonparametric probability analysis of scaffold-ranking library results to select the specific library for positional scanning.

some of the data points that the probabilistic analysis was able to take into account. On the basis of these data, optimal substitution groups for each position were selected to construct individual compounds. Natural gaps in the probability values indicated the selection of four functionalities for the $\mathbf{R}_{\mathbf{1}}$ position
(S-2-naphthylmethyl, R-2-naphthylmethyl, R-hydroxymethyl, and $S$-butyl), $S$-cyclohexyl for the $\mathbf{R}_{2}$ position, and four functionalities each for the $\mathbf{R}_{3}$ position ( $R$-4-hydroxybenzyl, $R$ 2-butyl, (S,R)-1-hydroxyethyl, and R-butyl) and $\mathbf{R}_{\mathbf{4}}$ position (3cyclopentyl-propyl, 3,4-dichlorophenethyl, 2-adamantan-1-ylethyl, and 4-tert-butyl-cyclohexyl-methyl). To reduce the number of individual compounds tested, structurally redundant choices with lower activity were eliminated. Moreover, to increase structural diversity in the $\mathbf{R}_{\mathbf{2}}$ position, the next most active functionality ( $R$-2-naphthylmethyl) was added. The final choices were then combined to synthesize $54(3 \times 2 \times 3 \times 3)$ individual, fully defined compounds; the TPI 2213 series (Table 1).

Testing of Individual 2213 Compounds. Ranking the 54 Individual 2213-Series Compounds for Antinociceptive Potency. To prioritize the samples to be evaluated in detail, each of the 54 compounds in the 2213 series $(10 \mathrm{mg} / \mathrm{kg}$, i.p.) was tested for analgesic activity. The combined time mice demonstrated to withdraw their tail was summed over the seven time points examined for each compound tested (Table 1 and Figure 6). Although the majority of samples produced significant antinociception as compared to baseline tailwithdrawal responses (one-way ANOVA, $F_{(55,408)}=15.6, p<$ 0.0001; Tukey's Multiple comparison post hoc test), seven of these individual samples produced antinociception equivalent to that of morphine $(P>0.05$, not significantly different; Tukey's Multiple comparison post hoc test): 2213-12, -17, -18, $-20,-21,-24$, and -32 . Accordingly, these compounds were selected for detailed characterization. Moreover, as compound $2213-23$ is a single position analog of 2213-24 (at the R4
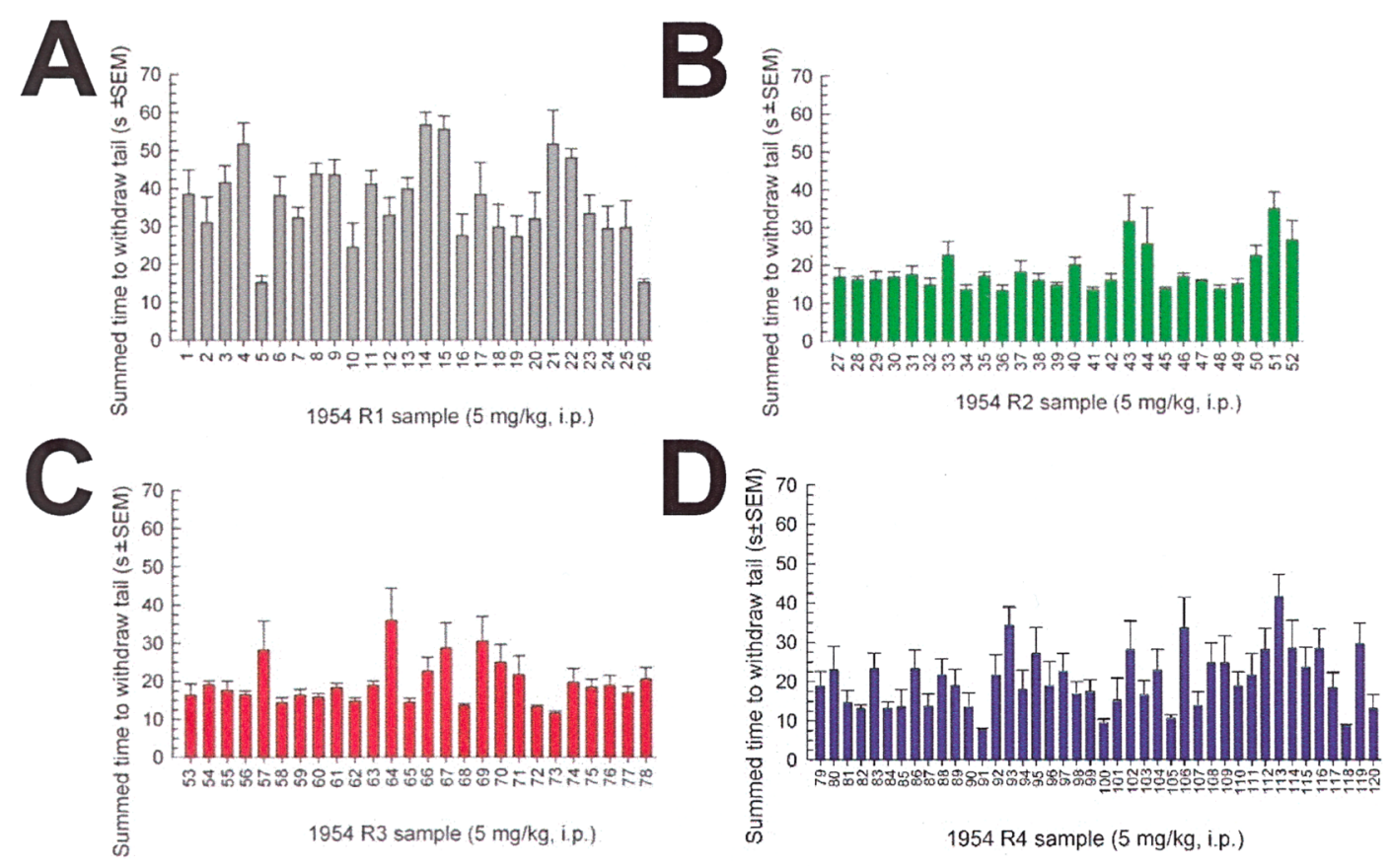

Figure 4. Positional scan screening of 1954-series OXXX samples: summed antinociception produced by 1954 series samples measured in the mouse $55^{\circ} \mathrm{C}$ warm water tail-withdrawal test across a 24-h period. (A) 1954 defined at position 1 (gray bars). (B) 1954 defined at position 2 (green bars). (C) 1954 defined at position 3 (red bars). (D) 1954 defined at position 4 (blue bars). The combined time to withdraw tails (s; $y$-axis) was calculated by taking the sum of the average tail-withdrawal latencies from each time point. Samples ( $x$-axis; see Table 2 below for full identities of the various chosen for the individual compounds prepared) were administered at a dose of $5 \mathrm{mg} / \mathrm{kg}$ i.p. for testing. Functionalities of key samples are described in simplified form for convenience; see Table 1 for complete descriptions. Data represent average $( \pm S E M)$ summed tail-withdrawal latencies calculated by taking the sum of the average tail-withdrawal latencies for each animal from each time point over a 24-h period. Samples administered at dose of $5 \mathrm{mg} / \mathrm{kg}$, i.p. Bars $=8$ mice each. 

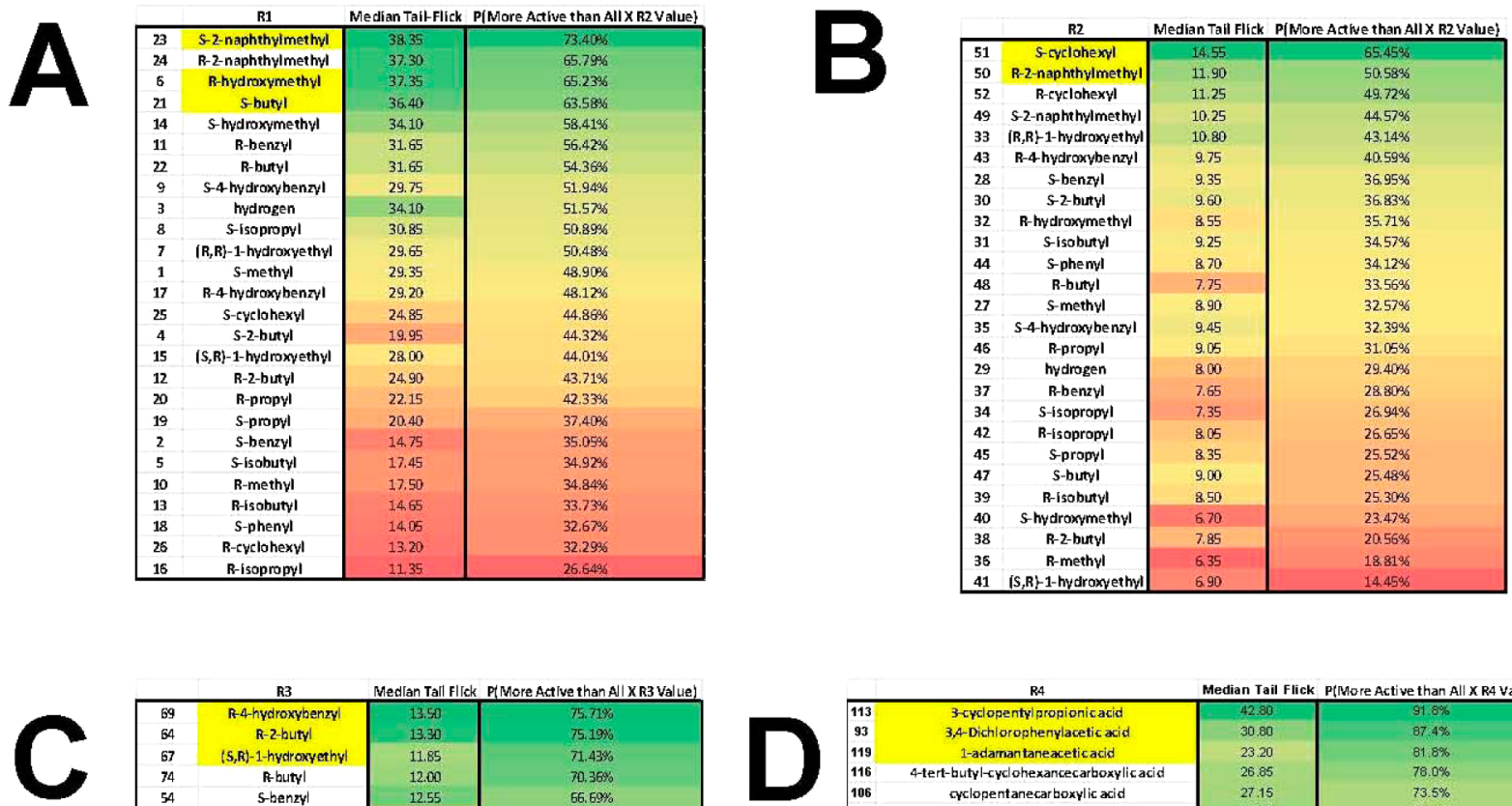

\begin{tabular}{|c|c|c|c|}
\hline & $\mathrm{R3}$ & Medlan Tall Fllck & P( More Actlve than A $X$ X R3 value) \\
\hline 69 & A-4hydroxybenzyl & 13.50 & $\overline{75.719 \%}$ \\
\hline 54 & R-2-butyl & 1330 & $75.19 \% \%$ \\
\hline 57 & $\mid \mathbf{s}, \mathbf{B})-1$-hydroxyethy & 11.85 & $71.43 \%$ \\
\hline 74 & F buttyl & 1200 & $70,36 \%$ \\
\hline 54 & sthenzyl & 12.55 & $66.69 \%$ \\
\hline 78 & R-eyclohexyl & 10.95 & $66.16 \%$ \\
\hline 76 & R-2-naphthylmethyl & 12.15 & $64.77 \%$ \\
\hline 66 & s-hydroxymethyl & 1110 & $60.35 \%$ \\
\hline 70 & s-phenyl & 11.85 & $58.95 \%$ \\
\hline 63 & fi-benzyl & 10.45 & $58.71 \%$ \\
\hline 75 & S-2-naphthy/ methyl & 9.80 & $57.55 \%$ \\
\hline 71 & s-propyl & 1020 & $55.76 \%$ \\
\hline 57 & S-Isobutity & 1105 & $53.06 \%$ \\
\hline 59 & {$[\mathbf{R}, \mathbf{B}\}-1-$-hydroxyethy } & 1070 & $52.48 \%$ \\
\hline$n$ & scyclohexyl & 1035 & $49.92 \%$ \\
\hline 55 & hydrogen & 9.25 & $48.61 \%$ \\
\hline 56 & s-2-butyl & 9.30 & $46.74 \%$ \\
\hline$n 2$ & f-propyl & RE & $42.03 \%$ \\
\hline 65 & R-Isohuty | & 9.15 & $41.69 \%$ \\
\hline 61 & s-4hydroxybenzyl & 8.95 & $40.35 \%$ \\
\hline 62 & R-methyl & 9.20 & $39.07 \%$ \\
\hline$\$$ & R-Isopropyl & 8.65 & $37.85 \%$ \\
\hline 58 & R-hydroxymethyl & 7.35 & $34.89 \%$ \\
\hline 50 & 5-Isopropyl & 8.75 & $34.79 \%$ \\
\hline 53 & s-methyl & 8.00 & $33.62 \%$ \\
\hline 73 & s-butyl & 7.70 & $27.57 \%$ \\
\hline
\end{tabular}
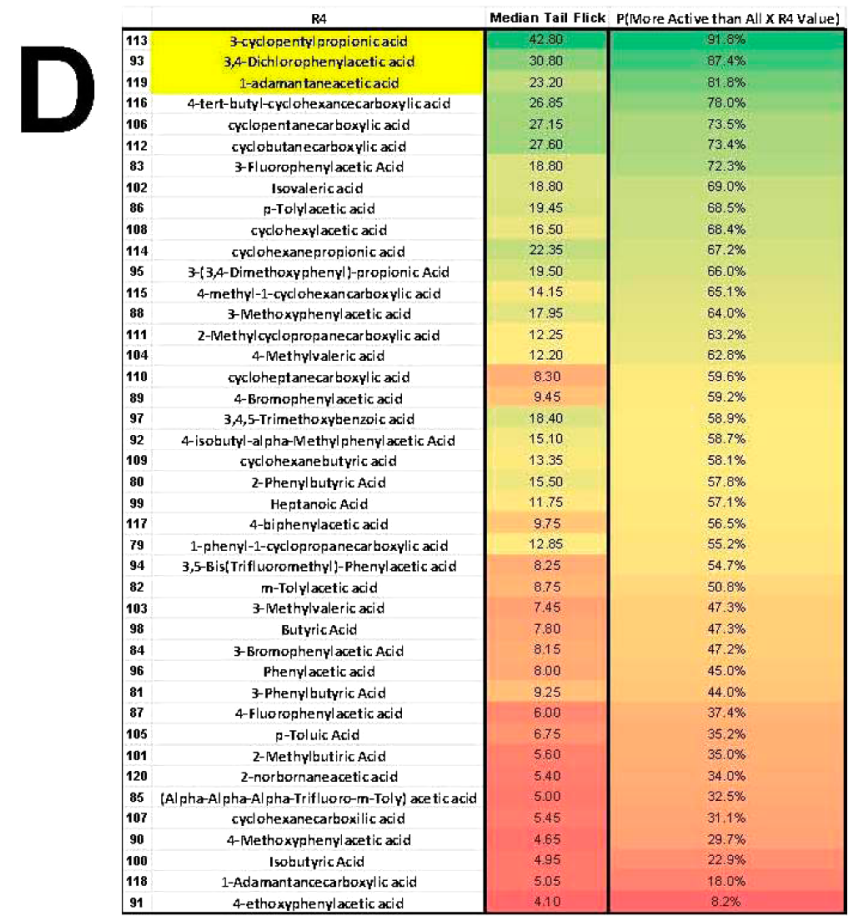

Figure 5. Nonparametric mathematical analysis of 1954-library positional scanning screening results used to select specific residues defining the 2213-series library of individual compounds at the $R_{1}$ position (A), the $R_{2}$ position (B), the $R_{3}$ position (C), and the $R_{4}$ position (D). Probability values were rank ordered and compared to obtained significances to confirm that there were no substantial discrepancies.

position) and 2213-32 (at the R2 position), and compound 2213-54 is a single position analog of $2213-18$ ( $\mathrm{R} 1$ position), 2213-23, and 2213-54, these were further examined (Figure 7).

The nine individual analogs that produced the greatest antinociceptive activity were selected for more detailed antinociceptive characterization in vivo. The Structures of these compounds are shown in Supporting Information Figure 1. Like morphine, each of the selected individual analogs exhibited antinociceptive activity in vivo, albeit with varying potencies (Table 2). All nine 2213-series compounds produced maximal antinociception 30 min after i.p. administration of each dose tested, returning to baseline levels $3 \mathrm{~h}$ after administration of the maximal dose tested $(10 \mathrm{mg} / \mathrm{kg}$, i.p.). Significant differences in potency were demonstrated by comparison of the shift in $\mathrm{ED}_{50}$ values by nonlinear regression modeling $\left(F_{(8,235)}=\right.$ 14.95; $P<0.0001$; Figure 7 ).
Opioid receptor selectivity in vivo of each 2213-series compound after i.p. administration was determined by pretreating mice with selective opioid receptor antagonists prior to testing in the $55{ }^{\circ} \mathrm{C}$ warm water tail-withdrawal assay as shown in Figure 8. Opioid receptor antagonists were administered at doses and in sufficient advance of TPI compounds to ensure inhibition of only one type of opioid receptor. Additionally, mice lacking the MOR demonstrated significant reductions in the effect of TPI 2213-18, -23, -24, and -54 . In contrast, pretreatment of wild-type mice with the KOR-selective antagonist nor-BNI or the DOR-selective antagonist naltrindole variably reduced antinociception produced by the nine different 2213-samples tested (Figure 8). These results suggest that the differing substitutions in the 2213 series samples resulted in differing responses to the three opioid receptors. Interestingly none of the compounds exhibited $K_{\mathrm{i}}$ 
Table 1. Individual TPI-2213 Series Compounds Synthesized

\begin{tabular}{|c|c|c|c|c|}
\hline ID & $\mathrm{R} 1$ & $\mathrm{R} 2$ & $\mathrm{R} 3$ & R4 \\
\hline 2213-1 & S-2-naphthyl methyl & $S$-cyclohexyl & $R$-4-hydroxybenzyl & 3-cyclopentyl-propyl \\
\hline $2213-2$ & S-2-naphthyl methyl & $S$-cyclohexyl & $R$-4-hydroxybenzyl & 3,4-dichlorophenethyl \\
\hline $2213-3$ & S-2-naphthyl methyl & $S$-cyclohexyl & $R$-4-hydroxybenzyl & 2-adamantan-1-yl-ethyl \\
\hline $2213-4$ & S-2-naphthyl methyl & $S$-cyclohexyl & $R$-2-butyl & 3-cyclopentyl-propyl \\
\hline $2213-5$ & S-2-naphthyl methyl & $S$-cyclohexyl & $R$-2-butyl & 3,4-dichlorophenethyl \\
\hline $2213-6$ & S-2-naphthyl methyl & $S$-cyclohexyl & $R$-2-butyl & 2-adamantan-1-yl-ethyl \\
\hline $2213-7$ & S-2-naphthyl methyl & $S$-cyclohexyl & $(S, R)$-1-hydroxyethyl & 3-cyclopentyl-propyl \\
\hline $2213-8$ & S-2-naphthyl methyl & $S$-cyclohexyl & $(S, R)$-1-hydroxyethyl & 3,4-dichlorophenethyl \\
\hline $2213-9$ & S-2-naphthyl methyl & $S$-cyclohexyl & $(S, R)$-1-hydroxyethyl & 2-adamantan-1-yl-ethyl \\
\hline $2213-10$ & $S$-2-naphthyl methyl & $R$-2-naphthylmethyl & $R$-4-hydroxybenzyl & 3-cyclopentyl-propyl \\
\hline $2213-11$ & $S$-2-naphthyl methyl & $R$-2-naphthylmethyl & $R$-4-hydroxybenzyl & 3,4-dichlorophenethyl \\
\hline $2213-12$ & S-2-naphthyl methyl & $R$-2-naphthylmethyl & $R$-4-hydroxybenzyl & 2-adamantan-1-yl-ethyl \\
\hline $2213-13$ & $S$-2-naphthyl methyl & $R$-2-naphthylmethyl & $R$-2-butyl & 3-cyclopentyl-propyl \\
\hline $2213-14$ & S-2-naphthyl methyl & $R$-2-naphthylmethyl & $R$-2-butyl & 3,4-dichlorophenethyl \\
\hline $2213-15$ & S-2-naphthyl methyl & $R$-2-naphthylmethyl & $R$-2-butyl & 2-adamantan-1-yl-ethyl \\
\hline $2213-16$ & S-2-naphthyl methyl & $R$-2-naphthylmethyl & $(S, R)$-1-hydroxyethyl & 3-cyclopentyl-propyl \\
\hline $2213-17$ & S-2-naphthyl methyl & $R$-2-naphthylmethyl & $(S, R)$-1-hydroxyethyl & 3,4-dichlorophenethyl \\
\hline 2213-18 & S-2-naphthyl methyl & $R$-2-naphthylmethyl & $(S, R)$-1-hydroxyethyl & 2-adamantan-1-yl-ethyl \\
\hline 2213-19 & $R$-hydroxymethyl & S-cyclohexyl & $R$-4-hydroxybenzyl & 3-cyclopentyl-propyl \\
\hline $2213-20$ & $R$-hydroxymethyl & $S$-cyclohexyl & $R$-4-hydroxybenzyl & 3,4-dichlorophenethyl \\
\hline $2213-21$ & $R$-hydroxymethyl & S-cyclohexyl & $R$-4-hydroxybenzyl & 2-adamantan-1-yl-ethyl \\
\hline $2213-22$ & $R$-hydroxymethyl & $S$-cyclohexyl & $R$-2-butyl & 3-cyclopentyl-propyl \\
\hline $2213-23$ & $R$-hydroxymethyl & S-cyclohexyl & $R$-2-butyl & 3,4-dichlorophenethyl \\
\hline $2213-24$ & $R$-hydroxymethyl & $S$-cyclohexyl & $R$-2-butyl & 2-adamantan-1-yl-ethyl \\
\hline $2213-25$ & $R$-hydroxymethyl & $S$-cyclohexyl & $(S, R)$-1-hydroxyethyl & 3-cyclopentyl-propyl \\
\hline $2213-26$ & $R$-hydroxymethyl & $S$-cyclohexyl & $(S, R)$-1-hydroxyethyl & 3,4-dichlorophenethyl \\
\hline $2213-27$ & $R$-hydroxymethyl & $S$-cyclohexyl & $(S, R)$-1-hydroxyethyl & 2-adamantan-1-yl-ethyl \\
\hline $2213-28$ & $R$-hydroxymethyl & $R$-2-naphthylmethyl & $R$-4-hydroxybenzyl & 3-cyclopentyl-propyl \\
\hline $2213-29$ & $R$-hydroxymethyl & $R$-2-naphthylmethyl & $R$-4-hydroxybenzyl & 3,4-dichlorophenethyl \\
\hline $2213-30$ & $R$-hydroxymethyl & $R$-2-naphthylmethyl & $R$-4-hydroxybenzyl & 2-adamantan-1-yl-ethyl \\
\hline $2213-31$ & $R$-hydroxymethyl & $R$-2-naphthylmethyl & $R$-2-butyl & 3-cyclopentyl-propyl \\
\hline $2213-32$ & $R$-hydroxymethyl & $R$-2-naphthylmethyl & $R$-2-butyl & 3,4-dichlorophenethyl \\
\hline 2213-33 & $R$-hydroxymethyl & $R$-2-naphthylmethyl & $R$-2-butyl & 2-adamantan-1-yl-ethyl \\
\hline 2213-34 & $R$-hydroxymethyl & $R$-2-naphthylmethyl & $(S, R)$-1-hydroxyethyl & 3-cyclopentyl-propyl \\
\hline $2213-35$ & $R$-hydroxymethyl & $R$-2-naphthylmethyl & $(S, R)$-1-hydroxyethyl & 3,4-dichlorophenethyl \\
\hline $2213-36$ & $R$-hydroxymethyl & $R$-2-naphthylmethyl & $(S, R)$-1-hydroxyethyl & 2-adamantan-1-yl-ethyl \\
\hline $2213-37$ & $S$-butyl & $S$-cyclohexyl & $R$-4-hydroxybenzyl & 3-cyclopentyl-propyl \\
\hline $2213-38$ & $S$-butyl & $S$-cyclohexyl & $R$-4-hydroxybenzyl & 3,4-dichlorophenethyl \\
\hline $2213-39$ & $S$-butyl & $S$-cyclohexyl & $R$-4-hydroxybenzyl & 2-adamantan-1-yl-ethyl \\
\hline $2213-40$ & $S$-butyl & $S$-cyclohexyl & $R$-2-butyl & 3-cyclopentyl-propyl \\
\hline $2213-41$ & $S$-butyl & $S$-cyclohexyl & $R$-2-butyl & 3,4-dichlorophenethyl \\
\hline $2213-42$ & $S$-butyl & $S$-cyclohexyl & $R$-2-butyl & 2-adamantan-1-yl-ethyl \\
\hline $2213-43$ & S-butyl & S-cyclohexyl & $(S, R)$-1-hydroxyethyl & 3-cyclopentyl-propyl \\
\hline $2213-44$ & $S$-butyl & $S$-cyclohexyl & $(S, R)$-1-hydroxyethyl & 3,4-dichlorophenethyl \\
\hline $2213-45$ & $S$-butyl & $S$-cyclohexyl & $(S, R)$-1-hydroxyethyl & 2-adamantan-1-yl-ethyl \\
\hline $2213-46$ & $S$-butyl & $R$-2-naphthylmethyl & $R$-4-hydroxybenzyl & 3-cyclopentyl-propyl \\
\hline $2213-47$ & S-butyl & $R$-2-naphthylmethyl & $R$-4-hydroxybenzyl & 3,4-dichlorophenethyl \\
\hline $2213-46$ & $S$-butyl & $R$-2-naphthylmethyl & $R$-4-hydroxybenzyl & 2-adamantan-1-yl-ethyl \\
\hline $2213-49$ & $S$-butyl & $R$-2-naphthylmethyl & $R$-2-butyl & 3-cyclopentyl-propyl \\
\hline $2213-50$ & $S$-butyl & $R$-2-naphthylmethyl & $R$-2-butyl & 3,4-dichlorophenethyl \\
\hline $2213-51$ & $S$-butyl & $R$-2-naphthylmethyl & $R$-2-butyl & 2-adamantan-1-yl-ethyl \\
\hline $2213-52$ & $S$-butyl & $R$-2-naphthylmethyl & $(S, R)$-1-hydroxyethyl & 3-cyclopentyl-propyl \\
\hline $2213-53$ & $S$-butyl & $R$-2-naphthylmethyl & $(S, R)$-1-hydroxyethyl & 3,4-dichlorophenethyl \\
\hline $2213-54$ & $S$-butyl & $R$-2-naphthylmethyl & $(S, R)$-1-hydroxyethyl & 2-adamantan-1-yl-ethyl \\
\hline
\end{tabular}

values less than $1 \mu \mathrm{M}$ (Supporting Information Table 1) at any of the three opioid receptors when tested in vitro.

The effects of the selected TPI-2213 compounds on respiration rate and both spontaneous and evoked locomotor activity were assessed. Mice were administered TPI-2213 compounds at twice the $\mathrm{ED}_{50}$ dose calculated from antinociceptive dose-response testing, or roughly corresponding to a maximal antinociceptive effect. Additional mice were treated with vehicle (10\% DMSO in $0.9 \%$ sterile saline, i.p.) or morphine $(10 \mathrm{mg} / \mathrm{kg}$, i.p.) for comparison. 


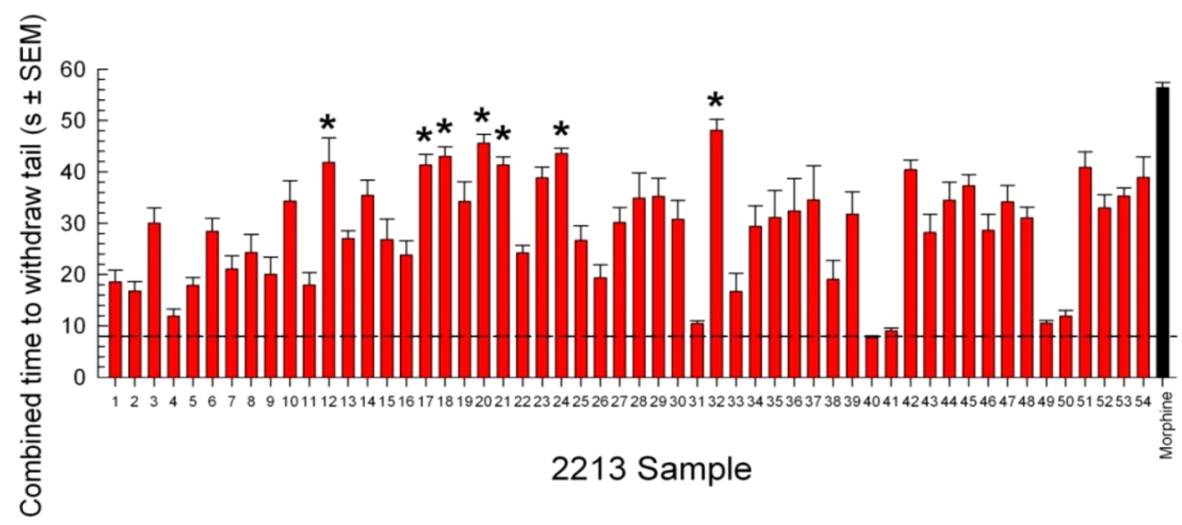

Figure 6. Screening of individually defined compounds using in vivo antinociception: summed antinociception produced by 2213 series samples (10 $\mathrm{mg} / \mathrm{kg}$, i.p.) measured in the mouse $55{ }^{\circ} \mathrm{C}$ warm water tail-withdrawal test across a 8 -h testing period. Vehicle effects (dashed horizontal line)and morphine $(10 \mathrm{mg} / \mathrm{kg}$, i.p., far right bar $)$ as a positive control. Data represent average $( \pm \mathrm{SEM})$ summed tail-withdrawal latencies Bars $=8 \mathrm{mice}$ each. *Significantly greater than vehicle effect, $p<0.05$, but not morphine; one-way ANOVA followed by Tukey Multiple comparison test.

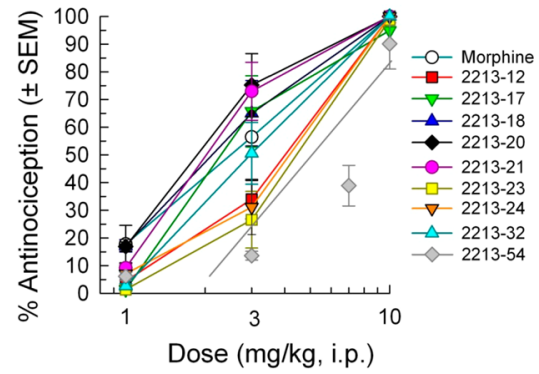

Figure 7. Dose-dependent antinociception produced by selected TPI2213 series compounds. Dose-response lines of morphine and TPI$2213-12,-17,-18,-20,-21,-23,-24,-32$, and -54 given by i.p. injection $30 \mathrm{~min}$ prior to testing in the mouse $55{ }^{\circ} \mathrm{C}$ warm water tail-withdrawal assay. Points $=8$ mice each. On the basis of the $\mathrm{ED}_{50}$ (and $95 \%$ confidence interval) values (Table 2), each 2213 compound exhibited similar antinociceptive potencies to morphine, with the exception of 2213-54, which displayed approximately half the potency of morphine.

Table 2. Antinociceptive Activity of Morphine and 9 Individual Selected Compounds from the TPI-2213 Series ${ }^{a}$

$\begin{array}{lc}\text { Compound } & E D_{50} \text { and } 95 \% \text { C.I. }(\mathrm{mg} / \mathrm{kg}, \text { i.p. }) \\ \text { Morphine } & 2.48(1.63-3.51) \\ 2213-12 & 3.41(2.93-3.98) \\ 2213-17 & 2.81(2.11-3.69) \\ 2213-18 & 2.30(1.72-2.95) \\ 2213-20 & 2.10(1.52-2.72) \\ 2213-21 & 2.36(1.83-2.96) \\ 2213-23 & 3.73(3.04-4.65) \\ 2213-24 & 3.43(2.79-4.25) \\ 2213-32 & 3.03(2.49-3.68) \\ 2213-54 & 5.72(4.29-8.36)\end{array}$

${ }^{a}$ Mice $(n=24)$ were administered a graded dose of morphine (as a positive control) or the TPI-2213 compound (i.p.) and tested in the $55^{\circ} \mathrm{C}$ warm-water tail-withdrawal assay 30 min later. $\mathrm{ED}_{50}$ and $95 \%$ confidence interval values (in $\mathrm{mg} / \mathrm{kg}$ ) are reported.

Morphine depressed respiration 22\% (Figure 9A), and induced spontaneous ambulatory activity 7.5 -fold as compared to the responses of saline-treated animals (Figure 9B). Many of the TPI 2213-lead compounds also significantly induced respiratory depression $\left(F_{(10,113)}=7.48, p<0.0001\right.$; Figure 9A), however 2213-17, 2213-20, and 2213-32 did not significantly alter breathing rate at this screening dose $(p>$
0.05; Dunnett's post hoc test). Likewise, the three compounds did not significantly impact spontaneous ambulatory activity at this same dose, whereas the other TPI 2213 lead compounds produced hypolocomotion $\left(F_{(9,102)}=4.03, p=0.0002\right.$, with Dunnett's post hoc test excluding morphine; Figure 9B). Locomotor activity, examined with the rotorod assay following treatment with eight of TPI 2213 lead compounds at their $\mathrm{ED}_{50 \times 2}$ dose indicated mild sedation by several of the compounds, although this was only significant with TPI 2213-20 and TPI 2213-32 (Figure 9C).

\section{DISCUSSION}

Two primary approaches are used to prepare and screen large numbers of compounds. These are (1) the massive parallel synthesis and robotic screening of large individual compound arrays and (2) the generation and screening of extremely large systemtically formatted mixture-based libraries. Once individual compounds are identified as therapeutically useful, their general target activities are improved by classic medicinal chemistry structure-activity relationship approaches prior to testing in vivo. However, it remains highly impractical for the majority of academic and small research organizations to make and screen such large numbers of compounds as individuals and can be in many cases prohibitively expensive as well. The large synthetic mixture based libraries utilized in thus current study were made using the solid phase parallel approach commonly known as the "tea bag" approach. ${ }^{21}$ Mixture-based combinatorial libraries made up of $10 \mathrm{~s}$ of thousands to millions of compounds were used in the current studies. $4,6,10-12,20$ The scaffold ranking approach ${ }^{7,11,16,17}$ was used to identify a promising scaffold, followed by a full positional scanning screen of the pyrrolidine bis-piperazines library (library number 1954). Consistent with previous demonstrations of use mixture based libraries directly in vivo ${ }^{7,8,11,16,17}$ the deconvolution of the 1954-library data resulted in the subsequent identification of a series of 54 individual compounds, eight of which proved equi-analgesic to morphine.

It is notable that the vast majority of novel compounds initially found to be promising are rejected at the in vivo stage of the drug discovery process. ${ }^{2,22-24}$ To circumvent the limitations of existing in vitro screening methods, we are able to test samples from our mixture-based combinatorial libraries directly in vivo for analgesic properties. When successful, this approach can be expected to enable the evaluation of very large 

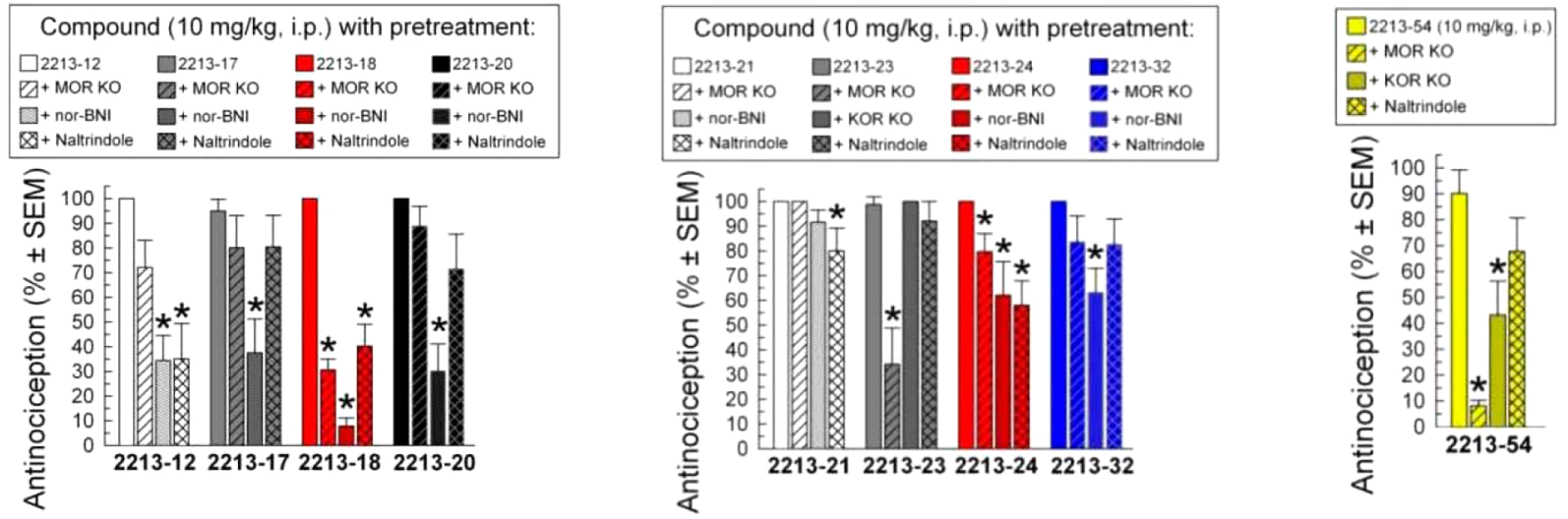

Figure 8. Opioid receptor selectivity of selected TPI-2213 series compounds. Bars $=8$ mice each. TPI-2213 compounds administered i.p. at $\mathrm{ED}_{90}$ dose (or higher) in MOR KO mice (striped bars) or wild-type mice with or without pretreatment with nor-BNI ( $10 \mathrm{mg} / \mathrm{kg}$, i.p., -24 h; criss crossed or naltrindole $(20 \mathrm{mg} / \mathrm{kg}$, i.p., $-20 \mathrm{~min}$, dotted bars). 2213-54 was tested in KOR KO mice instead of wild-type mice pretreated with nor-BNI. Antinociception was measured $30 \mathrm{~min}$ after administration of the TPI-2213 compound. $*=$ Significantly different from baseline latency. $\dagger=$ Significantly less than matching 2213 compound alone, $p<0.05$.

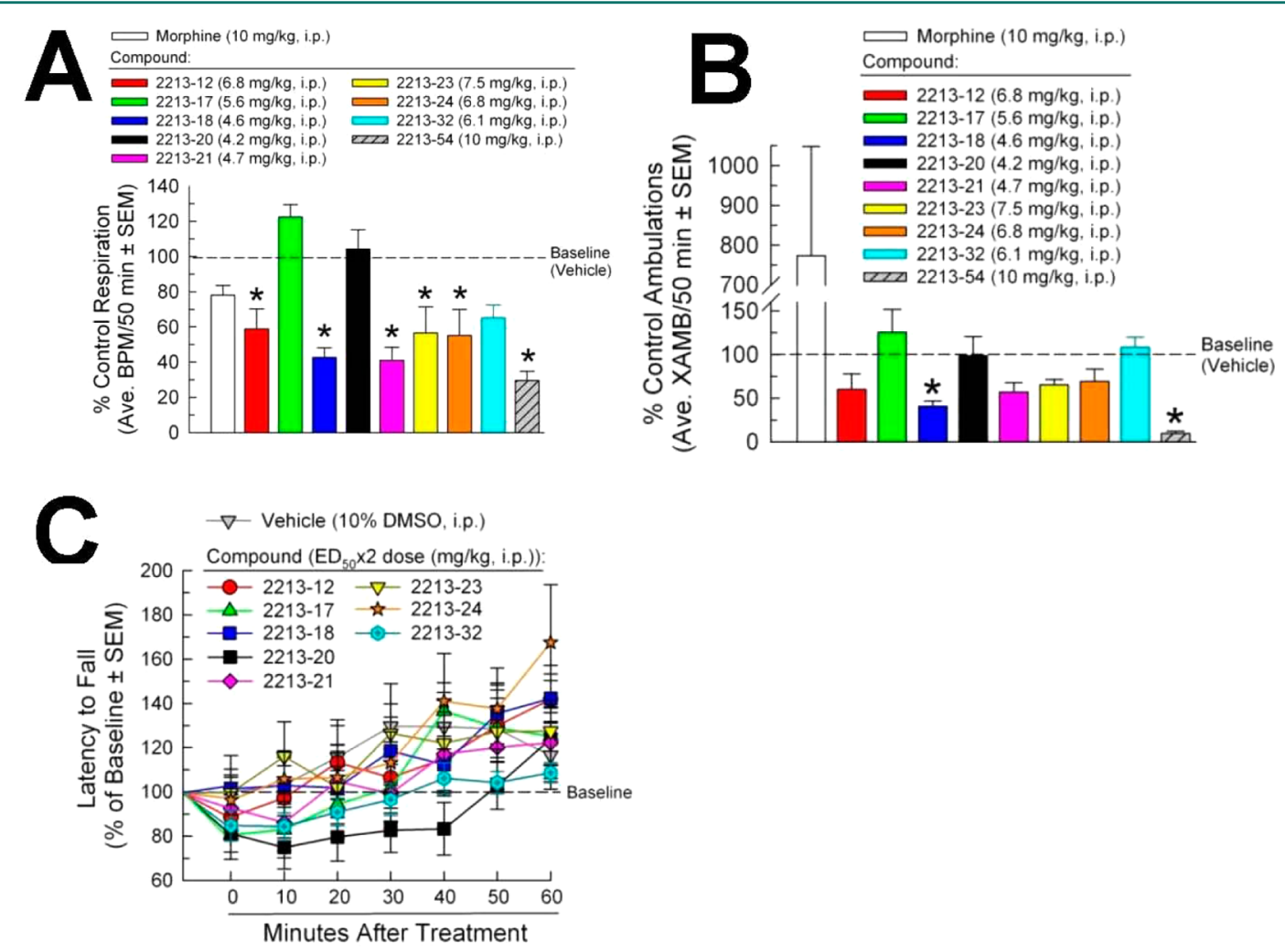

Figure 9. Liability screening of selected TPI-2213 individual compounds. Individual 2213-compounds were administered i.p. at an $\mathrm{ED}_{50} \times 2$ dose $($ see Table 2); vehicle (10\% DMSO, i.p.) and morphine (10 mg/kg, i.p.) were administered as controls. (A) Respiration response. Data represent average $( \pm \mathrm{SEM})$ respiration rate (in breaths per minute, BPM) over a $50 \mathrm{~min}$ period. (B) Spontaneous locomotor response. Data represent average $( \pm$ SEM) ambulation rate (in crossing ambulations per minute, XAMB) over a 50 min period. (C) Evoked locomotor response on rotorod (indicated by latency to fall from a rotorod as the percent change from baseline performance $/ 10 \mathrm{~min}$ ) of mice. Bars $=8$ mice each, except vehicle $(40 \mathrm{mice})$ and morphine $(24$ mice). Points $=8$ mice each, except vehicle (which was 16 mice). *Significantly different from response to vehicle, $p<0.05$, one-way ANOVA followed by Dunnett's post hoc test.

numbers of compounds while decreasing the failure rate inherent in the typical drug discovery process. Thus, the direct in vivo screening of mixture-based samples enables millions of acyclic and heterocyclic small molecules to be screened in animal models of disease. This would not be practical if one were to test even a fraction of the compounds screened in the present study. The outcome of this "high-throughput in vivo screening" process resulted in the early identification of favorable lead compounds with demonstrable and clear in vivo activity. These were more advanced in the drug discovery effort than the traditional HTS of individual compounds identified using in vitro processes. Many elements drive the value of this approach, including the inherent SAR data obtained directly from the initial positional scanning information set as well as the ability to identify hit or lead 
compounds to unknown targets that would not be identified through traditional HTS.

Compounds identified using in vivo HTS can act via (1) a single, known target, (2) multiple, known targets providing the overall effect, or (3) unknown target(s). Such studies can potentially lead to the identification of new biological targets and/or pathways for therapeutic intervention. The approach also identifies structurally novel compounds and is able to quickly detect potential problems (such as acute in vivo toxicity) that would not typically be recognized by traditional drug discovery approaches until much later in the drug discovery process. In vivo HTS is led completely by the overall activity of the compounds in the animal model utilized with no preconceived bias for the mechanism of action. Additionally, by screening directly in vivo, many drug development issues are addressed very early on, such as pharmacokinetics, blood-brain barrier penetration, and even bioavailability (if oral dosing is utilized). The overall in vivo HTS method allows for testing of many of these potential issues upon first testing the libraries. The current findings add to a growing body of work proving both the feasibility and utility of this approach. Previous screening by monitoring blood pressure and heart rate in rats after administration of 400 separate mixtures each of 130321 hexapeptides using an iterative versus the current positional scanning approach ${ }^{11}$ identified possible development candidates while simultaneously eliminating compounds with poor absorption, distribution, metabolism, and pharmacokinetic properties.

While the end result of the present search for low-liability analgesic agents was successful, additional detailed screening of libraries based on other scaffolds can be expected to provide additional enhanced antinociceptive agents. It should be noted that the identification of selective, novel opioid receptor antagonists is of potential therapeutic value. While not within the scope of the present study, the lack of antinociceptive response from select mixture samples in the 1954 library suggests the possibility of the presence potential antagonists using this approach. It is notable that opioid receptor antagonists have been identified from positional scanning and screening of synthetic peptide combinatorial libraries. ${ }^{25}$

In addition to using average or median values to rank-order scaffolds and positional scanning mixtures, an additional nonparametric confirmatory process was performed. Probability rank ordering at each position varied slightly from traditional median rank ordering, an indication of little asymmetric variability in the data, the probabilistic analysis was able to account for this effect and predict potentially useful functionality groups. On the basis of these analyses, the substitution groups for each position yielded confidence in the selection of active individual compounds. The implementation of nonparametric analysis increases the likelihood of success with the deconvolution process, as well as the use of combinatorial libraries themselves. In practical terms what this means is that one would not expect multiexponential increases in activity as we move from the all-X mixture, to the positional scanning libraries, to the individual compounds. In practice, because of the systematic formatting of the libraries one would typically anticipate steady increases in activity as the complexity of the mixtures is reduced. This was what was in fact found in the current study.

An exciting aspect of the present data stems from the promising in vivo activity of TPI 2213-17 (despite poor opioid receptor affinity demonstrated by in vitro $\mathrm{mu}$, delta, and kappa
RRA opiate testing). Results of this nature might otherwise have halted further examination of these compounds. A mechanism of action for the activity found in vivo is unclear at this juncture. It is possible that the activity is due to nonopioid-mediated interactions induced by the TPI compounds. Although the reduction (or, in other samples, elimination) of antinociception by pretreatment with opioidreceptor selective antagonists and/or testing in opioid receptor knock out mice strongly appears to implicate at least a partial opioid-receptor mediation of antinociception, there is precedence for clinical analgesics to work through a combination of opioid and nonopioid sites to alleviate pain. For example, tramadol mediates antinociception. through a combination of opioid and nonopioid (inhibition of monoamine uptake) mechanisms ${ }^{26}$ Further study of the interaction of the TPI2213 compounds with other targets such as TRPV-1 or monoamine transporters are planned in the future.

It also remains possible that the in vivo antinociception observed may be attributed to a metabolite of the lead TPI2213 compounds tested. As these metabolites would not be produced while utilizing an in vitro assay, potential metabolites could account for the opioid receptor activity, not unlike morphine- $6 \beta$-glucuronide demonstrating higher potency at the MOR receptor over that of the parent substrate, morphine, ${ }^{27}$ or metabolites of tramadol. ${ }^{28,29}$ Alternatively, it is also possible that the administration of the 2213-series compounds induce the release of an endogenous opioid, such as $\beta$-endorphin or an enkephalin. A number of compounds have been shown to induce the release of endorphins resulting in opioid-receptormediated antinociception, including the endothelin A receptor antagonist BQ $-123^{30}$ and agonists of endothelin B receptors. ${ }^{31}$ However, as the endogenous opioids produce all the detrimental effects of opioid agonists such as the respiratory depression induced by $\beta$-endorphin, ${ }^{32}$ it is unclear why TPI 2213-17 would produce opioid mediated antinociception without the opioid-mediated liabilities such as sedation typically attributed to activation of the kappa opioid receptor. A simpler alternative explanation may be that TPI 2213-17, -20 , or -32 poorly penetrate the central nervous system following peripheral administration, thereby restricting the activity of these compounds to the periphery after intraperitoneal administration. Peripherally restricted opioid agonists such as $\mathrm{N}$-methylmorphine have been shown to produce relief from some types of pain ${ }^{33,34}$ and could provide opioid analgesia with fewer liabilities of use, as they would be expected to lack many of the detrimental clinical effects mediated by mechanisms in the CNS. ${ }^{35}$ Though clearly important, the precise mechanism mediating the effects of the 2213-series compounds, is beyond the scope of this initial screening study. With specific compounds now identified, additional future work will further elucidate their mechanism of action.

In conclusion, the in vivo screening scaffold-based library samples tested directly in a mouse model directed us to use a positional scanning approach to screen the 120 mixture samples making up library 1954, which comprised in total 738192 compounds. The results yielded differentially active mixtures at each position that produced robust antinociception in the 55 ${ }^{\circ} \mathrm{C}$ warm water tail-withdrawal assay. The most active functionalities associated with each diversity position on the 1954 scaffold yielded the information necessary for the synthesis of 54 individual compounds, termed the TPI 2213 series. The most active of these compounds produced a dosedependent antinociception equivalent to morphine that was 
blocked by opioid-receptor selective antagonists. Importantly, TPI 2213-17 emerged from these compounds without causing respiratory depression or locomotor effects at therapeutically maximal doses, suggesting this may produce analgesia without the clinical liabilities presented by morphine. Beyond this, the results demonstrate the validity of using scaffold ranking of mixture-based combinatorial libraries and deconvolution by the use of the positional scanning approach following the in vivo testing results. This enabled the rapid identification of active individual compounds with enhanced potential therapeutic value and lower liabilities of use.

\section{EXPERIMENTAL PROCEDURES}

Synthesis of the Scaffold Libraries. The scaffold ranking library contains one sample representing each of the positional scanning libraries and these are termed all "X libraries" in that no specific position is individually defined (Figure 1B). Each sample contains an approximately equal molar amount of every compound in that library. For example, the sample 1954 in the scaffold ranking library contains 738192 compounds in approximately equal molar amounts. These samples were prepared by mixing the cleaved products of the complete positional scanning library, or by directly synthesizing the sample as a single mixture as was the case for sample 1954 . $^{7,8,15,16}$

Synthesis of the TPI 1954 Library. TPI 1954 is a positional scanning library comprised of 738192 pyrrolidine bis-piperazines (Figure 1; for a list of the functionalities at each of the four substitution sites, see Figure 4). The $R_{1}$ through $R_{3}$ functionalities are derived from 26 amino acids (Figure 4A-C and Figure $5 \mathrm{~A}-\mathrm{C}$ ) and the $\mathrm{R}_{4}$ functionalities are derived from 42 carboxylic acids (Figures 4D and 5D) such that the library contains $738192(26 \times 26 \times 26 \times 42)$ compounds systematically arranged into $120(26+26+26+42)$ mixture samples. The synthesis of the pyrrolidine bis-piperazine library, 1954, is described in Figure 1 and elsewhere. ${ }^{18}$ Briefly, the first 26 samples (Figures 4A and 5A) permit the assessment of the activity of the 26 different functionalities used at the $R_{1}$ position. In these 26 mixtures, each of the samples has a fixed functionality at the $R_{1}$ position and an equal molar mixture of the 26 functionalities at $R_{2}$ (Figure $5 B$ ), 26 functionalities at $\mathrm{R}_{3}$ (Figure $5 \mathrm{C}$ ), and 42 functionalities at $\mathrm{R}_{4}$ (Figure 5D). For example, sample 1 contains an equal molar mixture of $28,392(26 \times 26 \times 42)$ compounds all fixed with $S$ methyl at the $\mathrm{R}_{1}$ position, whereas sample 2 contains an equal molar mixture of 28392 compounds all fixed with $S$-benzyl at the $R_{1}$ position. In this way, samples 1 to 26 scan the first position by fixing each of the 26 samples with a different functionality at the $R_{1}$ position. The next 26 samples (samples 27 to 52 ) assess the functionalities at $R_{2}$ by fixing the $R_{2}$ position and having equal molar mixtures at the other three positions. Likewise, samples 53 to 78 assess the $R_{3}$ functionalities, and samples 79 to 120 assess the $R_{4}$ functionalities.

Synthesis of the 2213 Individual Compounds. The synthesis of the 54 individual compounds comprising the TPI 2213-series (Table 1) utilizes the synthetic scheme described in Figure 1. The solid-phase synthesis was performed using the tea-bag methodology. ${ }^{21}$ The synthesis of the pyrollidine bis piperazines was carried out as described earlier. ${ }^{18}$ Initially, 100 $\mathrm{mg}$ of $p$-methylbenzdrylamine (MBHA) resin $(1.1 \mathrm{mmol} / \mathrm{g}$, 100-200 mesh) was sealed in a mesh "tea-bag," neutralized with $5 \%$ diisopropylethylamine (DIEA) in dichloromethane
(DCM), and subsequently swelled with additional DCM washes. Boc-amino acids $\left(R_{1}\right.$, L-proline, $R_{2}$, and $\left.R_{3}\right)$ were coupled utilizing standard coupling procedures ( 6 equiv) with DIC (6 equiv) and HOBt (6 equiv) in DMF ( $0.1 \mathrm{M})$ for 120 min. All coupling reactions are monitored for completion by the ninhydrin test. After each coupling the Boc protecting group was removed with $55 \%$ trifluoroacetic Acid (TFA) in DCM for $30 \mathrm{~min}$ and subsequently neutralized with 5\% DIEA/ DCM $(3 \times)$. Ten equivalents of carboxylic acids $\left(R_{4}\right)$ were coupled using 10 equiv of each carboxylic acid in the presence of DIC (10 equiv) and HOBt (10 equiv) in DMF (0.1M) for $120 \mathrm{~min}$ (1, Figure 1). The reduction was performed in a 4000 $\mathrm{mL}$ Wilmad LabGlass vessel under nitrogen. A standard borane in 1.0 M Tetrahydrofuran complex solution was used in 40 fold excess for each amide bond. The vessel was heated to $65{ }^{\circ} \mathrm{C}$ and maintained at temperature for $72 \mathrm{~h}$. The solution is then discarded and the bags are washed with THF and methanol. Once completely dry, the bags are treated overnight with piperidine at $65{ }^{\circ} \mathrm{C}$ and washed several times with methanol, DMF, and DCM (2, Figure 1). Before proceeding, completion of reduction is monitored by a control cleavage and analyzed by LCMS. Diketopiperazine cyclization (3, Figure 1) was performed with a 5 fold excess of oxalyldiimidazole in a 0.1 $\mathrm{M}$ anhydrous DMF solution for each of the cyclization sites overnight. Following the cyclization, the bags are rinsed with DMF and DCM. Before proceeding, completion of cyclization is monitored by a control cleavage and analyzed by LCMS. The reduction (4, Figure 1) was performed in a $4000 \mathrm{~mL}$ Wilmad LabGlass vessel under nitrogen. A 1.0 M Tetrahydrofuran/ borane complex solution was used in 40 -fold excess for each amide bond. The vessel is heated to $65{ }^{\circ} \mathrm{C}$ and maintained at temperature for $72 \mathrm{~h}$. The solution is then discarded and the bags are washed with THF and methanol. Once completely dry, the bags are treated overnight with piperidine at $65{ }^{\circ} \mathrm{C}$ and washed several times with methanol, DMF and DCM. The resin is cleaved with $\mathrm{HF}$ in the presence of anisole in an ice bath at $0{ }^{\circ} \mathrm{C}$ for $7 \mathrm{~h}$ (5, Figure 1$)$.

LCMS Analysis. The purity and identity of all compounds was verified using a Shimadzu 2010 LCMS system, consisting of a LC-20AD binary solvent pumps, a DGU-20A degasser unit, a CTO-20A column oven, and a SIL-20A HT auto sampler. A Shimadzu SPD-M20A diode array detector was used for detections. A full spectra range of $190-600 \mathrm{~nm}$ was obtained during analysis. Chromatographic separations were obtained using a Phenomenex Luna C18 analytical column $(5 \mu \mathrm{m}, 50 \times$ $4.6 \mathrm{~mm}$ i.d.) The column was protected by a Phenomenex $\mathrm{C} 18$ column guard $(5 \mu \mathrm{m}, 4 \times 3.0 \mathrm{~mm}$ i.d.). All equipment was controlled and integrated by Shimadzu LCMS solutions software version 3. Mobile phases for LCMS analysis were HPLC grade or LCMS grade obtained from Sigma-Aldrich and Fisher Scientific. The mobile phases consisted of a mixture LCMS grade Acetonitrile/water (both with $0.1 \%$ formic acid for a $\mathrm{pH}$ of 2.7). The initial setting for analysis was set at $5 \%$ acetonitrile (v/v), then was linearly increased to $95 \%$ acetonitrile over $6 \mathrm{~min}$. The gradient was then held at 95\% acetonitrile for $2 \mathrm{~min}$ and then linearly decreased to $5 \%$ over $0.10 \mathrm{~min}$ and held until stop for an additional $1.90 \mathrm{~min}$. The total run time was equal to $12 \mathrm{~min}$. The total flow rate was set to $0.5 \mathrm{~mL} / \mathrm{min}$. The column oven and flow cell temperature for the diode array detector was set at $30{ }^{\circ} \mathrm{C}$. The auto sampler temperature was held at $15{ }^{\circ} \mathrm{C}$. $5 \mathrm{uL}$ was injected for analysis.

HPLC Purification. Compound purification was performed on a Shimadzu Prominence preparative HPLC system, 
consisting of LC-8A binary solvent pumps, a SCL-10A system controller, a SIL-10AP auto sampler, and a FRC-10A fraction collector. A Shimadzu SPD-20A UV detector was used for detection. The wavelength was set at $214 \mathrm{~nm}$ during analysis. Chromatographic separations were obtained using a Phenomenex Luna C18 preparative column $(5 \mu \mathrm{m}, 150 \times 21.5 \mathrm{~mm}$ i.d.). The column was protected by a Phenomenex C18 column guard $(5 \mu \mathrm{m}, 15 \times 21.2 \mathrm{~mm}$ i.d.). Prominence prep software was used to set all detection and collection parameters. The mobile phases for HPLC purification were HPLC grade obtained from Sigma-Aldrich and Fisher Scientific. The mobile phase consisted of a mixture of Acetonitrile/water (both with $0.1 \%$ formic acid). The initial setting for separation was set at $2 \%$ Acetonitrile, which was held for $2 \mathrm{~min}$, then the gradient was linearly increased to $20 \%$ Acetonitrile over $4 \mathrm{~min}$. The gradient was then linearly increased to 55\% Acetonitrile over 36 min. The HPLC system was set to automatically flush and reequilibrate the column after each run for a total of 4 column volumes. The total flow rate was set to $12 \mathrm{~mL} / \mathrm{min}$ and the total injection volume was set to $3900 \mu \mathrm{L}$. The fraction collector was set to collect from 6 to $40 \mathrm{~min}$. The corresponding fractions were then combined and lyophilized.

Key Compounds. 4-(((R)-1-(2-(Adamantan-1-yl)ethyl)-4((R)-1-(naphthalen-2-yl)-3-((S)-2-(((S)-2-(naphthalen-2ylmethyl)piperazin-1-yl)methyl)pyrrolidin-1-yl)propan-2-yl)piperazin-2-yl)methyl)phenol (12). Using the synthetic approach described in Figure 1 for the synthesis of pyrrolidine-bis-piperazines compound $\mathbf{1 2}$ was synthesized using the following reagents: Boc-L-2-naphthylalanine $\left(\mathrm{R}_{1}\right)$, Boc-D-2-naphthylalanine $\left(\mathrm{R}_{2}\right)$, Boc-D-tyrosine (2-Br-Z)-OH $\left(\mathrm{R}_{3}\right)$, and 1-adamantaneacetic acid $\left(\mathrm{R}_{4}\right)$. Final crude product was purified by HPLC as described above. LCMS (ESI+) Calcd for $\mathrm{C}_{56} \mathrm{H}_{71} \mathrm{~N}_{5} \mathrm{O}: 830.57$, found $[\mathrm{M}+\mathrm{H}]+$ : 830.30. LCMS retention time $(214 \mathrm{~nm}): 3.73$

(R)-1-((S)-1-(3,4-Dichlorophenethyl)-4-((R)-1-(naphthalen2-yl)-3-((S)-2-(((S)-2-(naphthalen-2-ylmethyl)piperazin-1-yl)methyl)pyrrolidin-1-yl)propan-2-yl)piperazin-2-yl)ethanol (17). Using the synthetic approach described in Figure 1 for the synthesis of pyrrolidine-bis-piperazines compound 17 was synthesized using the following reagents: Boc-L-2-naphthylalanine $\left(\mathrm{R}_{1}\right)$, Boc-D-2-naphthylalanine $\left(\mathrm{R}_{2}\right)$, Boc-D-threonine (Bzl)-OH $\left(\mathrm{R}_{3}\right)$, and 3,4-dichlorophenylacetic acid $\left(\mathrm{R}_{4}\right)$. LCMS (ESI+) Calcd for $\mathrm{C}_{47} \mathrm{H}_{57} \mathrm{Cl}_{2} \mathrm{~N}_{5} \mathrm{O}: 778.40$, found $[\mathrm{M}+$ $\mathrm{H}]+778.15$. LCMS retention time $(214 \mathrm{~nm}): 3.83$

(R)-1-((S)-1-(2-(Adamantan-1-yl)ethyl)-4-((R)-1-(naphthalen-2-yl)-3-((S)-2-(((S)-2-(naphthalen-2-ylmethyl)piperazin-1yl)methyl)pyrrolidin-1-yl)propan-2-yl)piperazin-2-yl)ethanol (18). Using the synthetic approach described in Figure 1 for the synthesis of pyrrolidine-bis-piperazines compound 18 was synthesized using the following reagents: Boc-L-2-naphthylalanine $\left(\mathrm{R}_{1}\right)$, Boc-D-2-naphthylalanine $\left(\mathrm{R}_{2}\right)$, Boc-D-threonine (Bzl)-OH $\left(\mathrm{R}_{3}\right)$, and 1-adamantaneacetic acid $\left(\mathrm{R}_{4}\right)$. Final crude product was purified by HPLC as described above. LCMS (ESI+) Calcd for $\mathrm{C}_{51} \mathrm{H}_{69} \mathrm{~N}_{5} \mathrm{O}: 768.55$, found $[\mathrm{M}+\mathrm{H}]+$ 768.25. LCMS retention time $(214 \mathrm{~nm}): 3.70$.

4-(((R) - 4-((S) - 1 - Cycloh exyl-3-((S) - 2 - ( ( R ) - 2 (hydroxymethyl)piperazin-1-yl)methyl)pyrrolidin-1-yl)propan-2-yl)-1-(3,4-dichlorophenethyl)piperazin-2-yl)methyl)phenol (20). Using the synthetic approach described in Figure 1 for the synthesis of pyrrolidine-bis-piperazines compound 20 was synthesized using the following reagents: Boc-L-Serine (Bzl) $\left(\mathrm{R}_{1}\right)$, Boc-L-cyclohexylalanine $\left(\mathrm{R}_{2}\right)$, Boc-Dtyrosine (2-Br-Z)-OH $\left(\mathrm{R}_{3}\right)$, and 3,4-dichlorophenylacetic acid
$\left(\mathrm{R}_{4}\right)$. Final crude product was purified by HPLC as described above. LCMS (ESI+) Calcd for $\mathrm{C}_{38} \mathrm{H}_{57} \mathrm{Cl}_{2} \mathrm{~N}_{5} \mathrm{O}_{2}$ : 686.40, found $[\mathrm{M}+\mathrm{H}]+686.15$. LCMS retention time $(214 \mathrm{~nm}): 3.38$.

4-((R)-1-(2-(Adamantan-1-yl)ethyl)-4-((S)-1-cyclohexyl-3((S)-2-(((R)-2-(hydroxymethyl)piperazin-1-yl)methyl)pyrrolidin-1-yl)propan-2-yl)piperazin-2-yl)methyl)phenol (21). Using the synthetic approach described in Figure 1 for the synthesis of pyrrolidine-bis-piperazines compound 21 was synthesized using the following reagents: Boc-L-serine (Bzl) $\left(R_{1}\right)$, Boc-L-cyclohexylalanine $\left(R_{2}\right)$, Boc-D-tyrosine (2-Br-Z)$\mathrm{OH}\left(\mathrm{R}_{3}\right)$, and 1-adamantaneacetic acid $\left(\mathrm{R}_{4}\right)$. Final crude product was purified by HPLC as described above. LCMS (ESI +) Calcd for $\mathrm{C}_{42} \mathrm{H}_{69} \mathrm{~N}_{5} \mathrm{O}_{2}: 676.55$, found $[\mathrm{M}+\mathrm{H}]+676.30$. LCMS retention time $(214 \mathrm{~nm}): 3.51$.

$((R)-1-(((S)-1-((S)-2-((R)-3-((R)-\sec -$ Butyl $)-4-(3,4-$ dichlorophenethyl)piperazin-1-yl)-3-cyclohexylpropyl)pyrrolidin-2-yl)methyl)piperazin-2-yl)methanol (23). Using the synthetic approach described in Figure 1 for the synthesis of pyrrolidine-bis-piperazines compound $\mathbf{2 3}$ was synthesized using the following reagents: Boc-L-serine $(\mathrm{Bzl})\left(\mathrm{R}_{1}\right)$, Boc-Lcyclohexylalanine $\left(R_{2}\right)$, Boc-D-isoleucine $\left(R_{3}\right)$, and 3,4-dichlorophenylacetic acid $\left(\mathrm{R}_{4}\right)$. Final crude product was purified by HPLC as described above. LCMS (ESI+) Calcd for $\mathrm{C}_{35} \mathrm{H}_{59} \mathrm{Cl}_{2} \mathrm{~N}_{5} \mathrm{O}:$ 636.42, found $[\mathrm{M}+\mathrm{H}]+$ 636.20. LCMS retention time $(214 \mathrm{~nm}): 3.34$.

$((R)-1-(((S)-1-((S)-2-((R)-4-(2-($ Adamantan-1-yl)ethyl)-3((R)-sec-butyl)piperazin-1-yl)-3-cyclohexylpropyl)pyrrolidin2-yl)methyl)piperazin-2-yl)methanol (24). Using the synthetic approach described in Figure 1 for the synthesis of pyrrolidinebis-piperazines compound $\mathbf{2 4}$ was synthesized using the following reagents: Boc-L-serine (Bzl) $\left(\mathrm{R}_{1}\right)$, Boc-L-cyclohexylalanine $\left(R_{2}\right)$, Boc-D-isoleucine $\left(R_{3}\right)$, and 1-adamantaneacetic acid $\left(\mathrm{R}_{4}\right)$. Final crude product was purified by HPLC as described above. LCMS (ESI+) Calcd for $\mathrm{C}_{39} \mathrm{H}_{71} \mathrm{~N}_{5} \mathrm{O}: 626.57$, found $[\mathrm{M}+\mathrm{H}]+626.30$. LCMS retention time $(214 \mathrm{~nm}): 3.60$.

$((R)-1$ - (( (S) - 1-((R)-2-((R)-3-((R)-sec-Butyl) -4-(3,4dichlorophenethyl)piperazin-1-yl)-3-(naphthalen-2-yl)propyl)pyrrolidin-2-yl)methyl)piperazin-2-yl)methanol (32). Using the synthetic approach described in Figure 1 for the synthesis of pyrrolidine-bis-piperazines compound 32 was synthesized using the following reagents: Boc-L-serine (Bzl) $\left(\mathrm{R}_{1}\right)$, Boc-D-2-naphthylalanine $\left(\mathrm{R}_{2}\right)$, Boc-D-isoleucine $\left(\mathrm{R}_{3}\right)$ and 3,4-dichlorophenylacetic acid $\left(R_{4}\right)$. Final crude product was purified by HPLC as described above. LCMS (ESI+) Calcd for $\mathrm{C}_{39} \mathrm{H}_{55} \mathrm{Cl}_{2} \mathrm{~N}_{5} \mathrm{O}: 680.38$, found $[\mathrm{M}+\mathrm{H}]+$ 680.10. LCMS retention time $(214 \mathrm{~nm}): 3.55$.

(R)-1-((S)-1-(2-(Adamantan-1-yl)ethyl)-4-((R)-1-((S)-2-(((S)2-butylpiperazin-1-yl)methyl)pyrrolidin-1-yl)-3-(naphthalen2-yl)propan-2-yl)piperazin-2-yl)ethanol (54). Using the synthetic approach described in Figure 1 for the synthesis of pyrrolidine-bis-piperazines compound 1 was synthesized using the following reagents: Boc-L-norleucine $\left(R_{1}\right)$, Boc-D-2naphthylalanine $\left(\mathrm{R}_{2}\right)$, Boc-D-threonine $(\mathrm{Bzl})\left(\mathrm{R}_{3}\right)$, and 1adamantaneacetic acid $\left(\mathrm{R}_{4}\right)$. Final crude product was purified by HPLC as described above. LCMS (ESI+) Calcd for $\mathrm{C}_{44} \mathrm{H}_{69} \mathrm{~N}_{5} \mathrm{O}: 684.55$, found $[\mathrm{M}+\mathrm{H}]+684.25$. LCMS retention time $(214 \mathrm{~nm}): 3.70$.

Animals. Experiments used male C57BL/6J mice (20-32 g each, Jackson Laboratories, Bar Harbor, ME). Additional tests used male mu-opioid receptor gene-disrupted "knockout" mice (MOR KO) or kappa-opioid receptor gene-disrupted "knockout" mice (KOR KO), obtained from a breeding colony established at the Torrey Pines Institute for Molecular Studies 
from homozygous breeding pairs of mice obtained from the Jackson Laboratory. Mice were housed four per cage in a temperature-controlled room. Cages were kept in a room with 12-h light/dark cycle with the lights on from 0700 to $1900 \mathrm{~h}$ and food and water available ad libitum. All procedures with mice were preapproved by the Torrey Pines Institute for Molecular Studies Institutional Animal Care Committee, operating under the OLAW approval number A4618-01, and in accordance with the 2002 National Institutes of Health Guide for the Care and Use of Laboratory Animals. Consistent with these guidelines, ongoing statistical testing of data collected was used to minimize the number of animals used, within the constraints of necessary statistical power.

Chemicals. In all assays, TPI compounds were dissolved in $10 \%$ dimethyl sulfoxide, a concentration that did not produce any detectable behavioral effect. Morphine sulfate, naloxone, nor-binaltorphimine (nor-BNI), and naltrindole were purchased from Sigma-Aldrich (St. Louis, MO) and dissolved in $0.9 \%$ sterile saline.

Opioid Receptor Binding to Murine Brain Membranes. The ability of TPI 2213 library samples to bind to the three opioid receptors was determined by incubating membrane protein with a receptor-selective radiolabeled ligands and a $500 \mu \mathrm{M}$ concentration of one of the TPI 2213 samples as described previously. ${ }^{7}$ Incubation times of $60 \mathrm{~min}$ were used for the MOR-selective peptide $\left[{ }^{3} \mathrm{H}\right]\left[\mathrm{D}-\mathrm{Ala}^{2},(\mathrm{Me})\right.$ $\left.\mathrm{Phe}^{4}, \mathrm{Gly}(\mathrm{ol})^{5}\right]$ enkephalin $\left(\left[{ }^{3} \mathrm{H}\right] \mathrm{DAMGO}\right)$ and $120 \mathrm{~min}$ for the delta-opioid receptor (DOR) selective peptide $\left[{ }^{3} \mathrm{H}\right][\mathrm{D}-$ $\left.\mathrm{Pen}^{2}, \mathrm{Phe}^{4}, \mathrm{D}-\mathrm{Pen}^{5}\right]$ enkephalin $\left(\left[{ }^{3} \mathrm{H}\right] \mathrm{DPDPE}\right)$ using rat brain homogenates and the kappa-opioid receptor (KOR) selective ligand $\left[{ }^{3} \mathrm{H}\right] \mathrm{U} 69,593$ at final concentrations of $1-2 \mathrm{nM}$, in guinea pig brain homogenates. $4,5,36$

Antinociceptive Testing. The $55{ }^{\circ} \mathrm{C}$ warm-water tailwithdrawal assay was performed with mice as previously described. ${ }^{16}$ Briefly, water heated to $55{ }^{\circ} \mathrm{C}$ acted as a nociceptive stimulus with the latency to withdraw the tail was taken as the end point. Mice showing no response within $5 \mathrm{~s}$ during the determination of baseline responses were excluded from the experiment. After determining baseline control responses, mice were administered vehicle or graded doses of morphine or a TPI sample. All samples were each given as single intraperitoneal (i.p.) injections with tail withdrawal latencies measured $0.5,1,2,3.5,5,8$, and $24 \mathrm{~h}$ postadministration unless otherwise stated. A cutoff of $15 \mathrm{~s}$ was used to avoid tissue damage; those mice failing to withdraw their tails within this time were assigned a maximal antinociceptive score of $100 \%$. In the receptor selectivity studies, the KOR-selective antagonist nor-BNI $(10 \mathrm{mg} / \mathrm{kg}$, i.p.) was injected $24 \mathrm{~h}$ before TPI sample administration, whereas the DOR-selective antagonist naltrindole $(20 \mathrm{mg} / \mathrm{kg}$, i.p.) was administered $20 \mathrm{~min}$ prior to administration of the TPI sample.

For scaffold and positional screening studies, results are presented as the sum of average responses at each time point across all seven time points tested. For more detailed analysis across time (selected TPI 2213-series individual samples), antinociception at each time point was calculated as follows: \% antinociception $=100($ test latency - control latency $) /(15-$ control latency).

Respiratory Effects. Respiration rates were recorded using the automated, computer-controlled Comprehensive Lab Animal Monitoring System (CLAMS) apparatus (Columbus Instruments, Columbus, $\mathrm{OH}$ ) as described previously. ${ }^{16}$ On the day of the test, male C57BL/6J mice were habituated for 60 min in the apparatus cages, then administered (i.p.) vehicle or a single dose of morphine or TPI sample. Following administration, mice were returned to chambers for $90 \mathrm{~min}$ with respiration rate (breaths/min, or BPM) measured in 30-s intervals.

Locomotor Activity. Spontaneous locomotor activity of mice was simultaneously monitored in the CLAMS apparatus for $90 \mathrm{~min}$ after i.p. administration of vehicle, morphine (10 $\mathrm{mg} / \mathrm{kg}$, i.p.), or TPI sample. As the animal moved through the cage, infrared beams spaced every half inch along the longitudinal axis were broken, allowing the calculation of spontaneous locomotor activity (as ambulations) from adjacent beam breaks as described earlier. ${ }^{17}$

Possible sedative effects of the TPI-2213 individual samples were assessed by rotorod performance, as modified from previous protocols. ${ }^{37}$ Following seven habituation trials (the last utilized as a baseline measure of rotorod performance), mice were administered vehicle or a TPI-2213 series compound (i.p.) and assessed after $10 \mathrm{~min}$ in accelerated speed trials (180 $\mathrm{s}$ max. latency at $0-20 \mathrm{rpm}$ ) over a $60 \mathrm{~min}$ period. Decreased latencies to fall in the rotorod test indicate impaired motor performance. Data are expressed as the percent change from baseline performance.

Statistical Analysis. All dose-response lines were analyzed by regression and $\mathrm{ED}_{50}$ (dose producing 50\% antinociception) values and $95 \%$ confidence limits determined using each individual data point by Prism5.0 software. Statistical significance of $\mathrm{ED}_{50}$ values was determined by evaluation of the $\mathrm{ED}_{50}$ value shift via nonlinear regression modeling using Prism 5.0. Student's $t$ tests comparing baseline and posttreatment tail-withdrawal latencies were used to determine statistical significance for all tail-withdrawal data. ${ }^{38}$ Student's $t$ tests were also used to determine statistical significance of summarized antinociceptive effects of each individual sample against the same effect of morphine. Ranking of library samples (see Figure 2) was performed with one-way ANOVA, with significant effects further analyzed by Dunnet's multiple comparison post hoc testing using Prism 5.0 software. Data for respiration and ambulation effects were analyzed with oneway ANOVA using Prism 5.0, with significant effects further analyzed by Tukey's HSD post hoc testing. Rotorod data were analyzed via repeated measures ANOVA, with drug treatment condition as a between-groups factor. For all repeated measures ANOVAs simple main effects and simple main effect contrasts are presented following significant interactions. Where appropriate, Tukey's HSD post hoc tests were used to assess group differences. All data are presented as mean \pm SEM, with significance set at $p \leq 0.05$.

Nonparametric Mathematical Analysis. For a given sample $X$ and control $Y$, the probability density of the random variables $X$ and $Y$ was estimated using the median, quartiles, and extrema (i.e., the five number summary) of their respective data sets. Then, the probability, $P$, that the random variable $Z=$ $X-Y$ is greater than zero (i.e., the probability that a randomly chosen sample value exceeds a randomly chosen control value) was calculated using Monte Carlo simulation on the estimated distributions. Finally, these probability values were rank ordered and compared to obtained significances, which were compared with the above statistical analyses to confirm that there were no substantial discrepancies. 


\section{ASSOCIATED CONTENT}

\section{S Supporting Information}

The Supporting Information is available free of charge on the ACS Publications website at DOI: 10.1021/acscombsci.5b00126.

Ten small-molecule libraries samples contained in the Scaffold Ranking Library, values for the inhibition of mu-, delta-, and kappa-opioid receptor-selective radioligand binding to membrane protein by samples from TPI2213-series, and chemical structures of individual compounds (PDF)

\section{AUTHOR INFORMATION}

\section{Corresponding Author}

*Phone: 772-345-4580. Fax 772-345-3649. E-mail: houghten@ tpims.org.

\section{Present Address}

Jay P. McLaughlin and Shainnel Eans: University of Florida, Department of Pharmacodynamics, 1345 Center Drive, P.O. Box 100487, Gainesville, FL 32610.

\section{Author Contributions}

R.A.H., M.G., C.T.D., J.P.M., R.G.S., A.N., and C.D. conceived and designed experiments. T.L., M.L.G., S.O.E., E.M., and C.T.D. performed the experiments. J.P.M., M.G., C.T.D., R.G.S., T.L., G.W., and R.A.H. wrote the manuscript and Supporting Information

\section{Funding}

This work was supported by NIDA grant R01DA031370 (to RAH) and by the State of Florida, Executive Office of the Governor's Department of Economic Opportunity.

\section{Notes}

The authors declare no competing financial interest.

\section{ABBREVIATIONS}

$\mathrm{Abu}$, aminobutyric acid; ANOVA, analysis of variance; BBB, blood-brain barrier; Boc, tert-butyloxycarbonyl; CLAMS, comprehensive laboratory animal monitoring system; CNS, central nervous system; DAMGO, [D-Ala2,(Me) Phe4,Gly(ol)5] enkephalin; DOR, delta-opioid receptor; DPDPE, [DPen2,Phe4,D-Pen5] enkephalin; $\mathrm{ED}_{50}$, effective dose to produce $50 \%$ antinociception; HSD, honestly significant difference; Hyp, hydroxyproline; i.c.v, intracerebroventricular; i.p, intraperitoneal; KOR, kappa-opioid receptor; LC-MS, liquidchromatography mass-spectrometry; MBHA, 4-methylbenzylhydrylamine; MOR, mu-opioid receptor; Nle, norleucine; norBNI, norbinaltorphimine; Nva, norvaline; PS-SL, positional scanning synthetic library; RP-HPLC, reversed-phase highperformance liquid chromatography; s.c., subcutaneous; U50,488, ( \pm -trans-3,4-dichloro-N-methyl-N-[2-(1pyrrolidinyl)cyclohexyl] benzeneacetamide; U69,593, (+)- $(5 \alpha, 7 \alpha, 8 \beta)-N$-methyl- $N$-[7-(1-pyrrolidinyl)-1-oxaspiro[4.5]dec-8-yl]-benzeneacetamide

\section{REFERENCES}

(1) Yaksh, T. L.; Wallace, M. S. Opioids, analgesia, and pain management. In Goodman and Gilman's The Pharmacological Basis of Therapeutics,12th ed.; Brunton, L. L., Chabner, B. A., Knollmann, B. C., Eds.; McGraw-Hill: New York, 2011; pp 481-525.

(2) Hefti, F. F. Requirements for a lead compound to become a clinical candidate. BMC Neurosci. 2008, 9 (Suppl 3), S7.

(3) Pinilla, C.; Appel, J. R.; Blanc, P.; Houghten, R. A. Rapid identification of high affinity peptide ligands using positional scanning synthetic peptide combinatorial libraries. Biotechniques 1992, 13 (6), 901-5.

(4) Dooley, C. T.; Houghten, R. A. The use of positional scanning synthetic peptide combinatorial libraries for the rapid determination of opioid receptor ligands. Life Sci. 1993, 52, 1509-1517.

(5) Dooley, C. T.; Ny, P.; Bidlack, J. M.; Houghten, R. A. Selective ligands for the mu, delta, and kappa opioid receptors identified from a single tetrapeptide positional scanning combinatorial library. J. Biol. Chem. 1998, 273, 18848-18856.

(6) Houghten, R. A.; Pinilla, C.; Appel, J. R.; Blondelle, S. E.; Dooley, C. T.; Eichler, J.; Nefzi, A.; Ostresh, J. M. Mixture-based synthetic combinatorial libraries. J. Med. Chem. 1999, 42, 3743-3778.

(7) Houghten, R. A.; Pinilla, C.; Giulianotti, M. A.; Appel, J. R.; Dooley, C. T.; Nefzi, A.; Ostresh, J. M.; Yu, Y.; Maggiora, G. M.; Medina-Franco, J. L.; Brunner, D.; Schneider, J. Strategies for the use of mixture-based synthetic combinatorial libraries: scaffold ranking, direct testing in vivo, and enhanced deconvolution by computational methods. J. Comb. Chem. 2008, 10, 3-19.

(8) Wu, J.; Zhang, Y.; Maida, L. E.; Santos, R. G.; Welmaker, G. S.; LaVoi, T. M.; Nefzi, A.; Yu, Y.; Houghten, R. A.; Toll, L.; Giulianotti, M. A. Scaffold ranking and positional scanning utilized in the discovery of nAChR-selective compounds suitable for optimization studies. J. Med. Chem. 2013, 56 (24), 10103-10117.

(9) Chang, Y. P.; Banerjee, J.; Dowell, C.; Wu, J.; Gyanda, R.; Houghten, R. A.; Toll, L.; McIntosh, J. M.; Armishaw, C. J. Discovery of a potent and selective $\alpha 3 \beta 4$ nicotinic acetylcholine receptor antagonist from an $\alpha$-conotoxin synthetic combinatorial library. J. Med. Chem. 2014, 57 (8), 3511-3521.

(10) Houghten, R. A.; Pinilla, C.; Blondelle, S. E.; Appel, J. R.; Dooley, C. T.; Cuervo, J. H. Generation and use of synthetic peptide combinatorial libraries for basic research and drug discovery. Nature 1991, 354, 84-86.

(11) Houghten, R. A. Soluble combinatorial libraries: extending the range and repertoire of chemical diversity. Methods 1994, 6, 354-360.

(12) Nefzi, A.; Ostresh, J. M.; Yu, Y.; Houghten, R. A. Combinatorial chemistry: libraries from libraries, the art of the diversity-oriented transformation of resin-bound peptides and chiral polyamides to low molecular weight acyclic and heterocyclic compounds. J. Org. Chem. 2004, 69, 3603-3609.

(13) Judkowski, J.; Bunying, A.; Ge, F.; Appel, J. R.; Law, K.; Sharma, A.; Raja- Gabaglia, C.; Norori, P.; Santos, R. G.; Giulianotti, M. A.; Slifka, M. K.; Douek, D. C.; Graham, B. S.; Pinilla, C. GM-CSF Production Allows the Identificat Immunoprevalent Antigens Recognized by Human CD4+ T Cells Following Smallpox Vaccination. PLoS One 2011, 6 (9), No. e24091.

(14) Santos, R. G.; Giulianotti, M. A.; Dooley, C. T.; Pinalla, C.; Appel, J. R.; Houghten, R. A. Use and implications of the harmonic mean model on mixtures for basic research and drug discovery. ACS Comb. Sci. 2011, 13 (3), 337-44.

(15) Santos, R. G.; Appel, J. R.; Giulianotti, M. A.; Edwards, B. S.; Sklar, L. A.; Houghten, R. A.; Pinilla, C. The mathematics of a successful deconvolution: a quantitative assessment of mixture-based combinatorial libraries screened against two formylpeptide receptors. Molecules 2013, 18, 6408-6424.

(16) Reilley, K. J.; Giulianotti, M. A.; Dooley, C. T.; Nefzi, A.; McLaughlin, J. P.; Houghten, R. A. Identification of two novel, potent, low-liability antinociceptive compounds from the direct in vivo screening of a large mixture-based combinatorial library. AAPS J. 2010, 12 (3), 318-329.

(17) Armishaw, C. J.; Banerjee, J.; Ganno, M. L.; Reilley, K. J.; Eans, S. O.; Mizrachi, E.; Gyanda, R.; Hoot, M. R.; Houghten, R. A.; McLaughlin, J. P. Discovery of novel antinociceptive $\alpha$-conotoxin analogues from the direct in vivo screening of a synthetic mixturebased combinatorial library. ACS Comb. Sci. 2013, 15 (3), 153-161.

(18) Hensler, M. E.; Bernstein, G.; Nizet, V.; Nefzi, A. Pyrrolidine bis-cyclic guanidines with antimicrobial activity against drug-resistant gram positive pathogens identified from a mixture-based combinatorial library. Bioorg. Med. Chem. Lett. 2006, 16, 5073-5079. 
(19) Pinilla, C.; Appel, J. R.; Blondelle, S. E.; Dooley, C. T.; Eichler, J.; Ostresh, J. M.; Houghten, R. A. Versatility of positional scanning synthetic combinatorial libraries for the identification of individual compounds. Drug Dev. Res. 1994, 33, 133-145.

(20) Nefzi, A.; Appel, J.; Arutyunyan, S.; Houghten, R. A. Parallel synthesis of chiral pentaamines and pyrrolidine containing bisheterocyclic libraries. Multiple scaffolds with multiple building blocks: A double diversity for the identification of new antitubercular compounds. Bioorg. Med. Chem. Lett. 2009, 19, 5169-5175.

(21) Houghten, R.A. General Method for the Rapid solid-phase synthesis of large numbers of individual peptides. Proc. Natl. Acad. Sci. U. S. A. 1985, 82, 5131-5135.

(22) Dooley, C. T.; Houghten, R. A. Synthesis and screening of positional scanning combinatorial libraries. In Methods in Molecular Biology, Vol. 87: Combinatorial Peptide Library Protocols; Cabilly, S., Ed.; Humana Press, Inc.: Totowa, NJ, pp 13-24, 1998; PMID: 9523255.

(23) Carroll, F. I.; Houghten, R. A. From rapid in vitro screening to rapid in vivo screening in the drug discovery process. Neuropsychopharmacology 2009, 34, 251-252.

(24) Dolle, R. E. Comprehensive survey of combinatorial library synthesis: 2004. J. Comb. Chem. 2005, 7, 739-98.

(25) Dooley, C. T.; Chung, N. N.; Schiller, P. W.; Houghten, R. A. Acetalins: opioid receptor antagonists determined through the use of synthetic peptides combinatorial libraries. Proc. Natl. Acad. Sci. U. S. A. 1993, 90, 10811-10815.

(26) Raffa, R. B.; Friderichs, E.; Reimann, W.; Shank, R. P.; Codd, E. E.; Vaught, J. L. Opioid and nonopioid compounds independently contribute to the mechanism of action of tramadol, an 'atypical' opioid analgesic. J. Pharmacol Exp Ther. 1992, 260 (1), 275-285.

(27) Paul, D.; Standifer, K. M.; Inturrisi, C. E.; Pasternak, G. W. Pharmacological characterization of morphine- $6 \beta$-glucuronide: A very potent morphine metabolite. J. Pharmacol Exp Ther. 1989, 251, 477483.

(28) Klotz, U. Tramadol-the impact of its pharmacokinetic and pharmacodynamics properties on the clinical management of pain. Arzneim. Forsch. 2003, 53 (10), 681-687.

(29) Reeves, R. R.; Burke, R. S. Tramadol: basic pharmacology and emerging concepts. Drugs Today 2008, 44 (11), 827-836.

(30) Quang, P. N.; Schmidt, B. L. Endothelin-A receptor antagonism attenuates carcinoma-induced pain through opioids in mice. J. Pain 2010, 11 (7), 663-671.

(31) Quang, P. N.; Schmidt, B. L. Peripheral endothelin B receptor agonist-induced antinociception involves endogenous opioids in mice. Pain 2010, 149 (2), 254-262.

(32) Unal, C. B.; Owen, M. D.; Millington, W. R. Beta-endorphininduced cardiorespiratory depression is inhibited by glycyl-L-glutamine, a dipeptide derived from beta-endorphin processing. J. Pharmacol Exp Ther. 1994, 271, 952-958.

(33) Smith, T. W.; Buchan, P.; Parsons, D. N.; Wilkinson, S. Peripheral antinociceptive effects of N-methyl morphine. Life Sci. 1982, 31, 1205-1208.

(34) Oluyomi, A. O.; Hart, S. L.; Smith, T. W. Differential antinociceptive effects of morphine and methylmorphine in the formalin test. Pain 1992, 49, 415-418.

(35) DeHaven-Hudkins, D. L.; Dolle, R. E. Peripherally restricted opioid agonists as novel analgesic agents. Curr. Pharm. Des. 2004, 10, 743-757.

(36) Dooley, C. T.; Chung, N. N.; Wilkes, B. C.; Schiller, P. W.; Bidlack, J. M.; Pasternak, G. W.; Houghten, R. A. An all D-amino acid opioid peptide with central analgesic activity from a combinatorial library. Science 1994, 266, 2019-2022.

(37) Eans, S. O.; Ganno, M. L.; Reilley, K. J.; Patkar, K. A.; Senadheera, S. N.; Aldrich, J. V.; McLaughlin, J. P. The macrocyclic tetrapeptide [D-Trp]CJ-15,208 produces short-acting $\kappa$ opioid receptor antagonism in the CNS after oral administration. Br. J. Pharmacol. 2013, 169 (2), 426-436.
(38) Fay, M. P.; Proschan, M. A. Wilcoxon-Mann-Whitney or t-test? On assumptions for hypothesis tests and multiple interpretations of decision rules. Statistics Surveys 2010, 4, 1. 